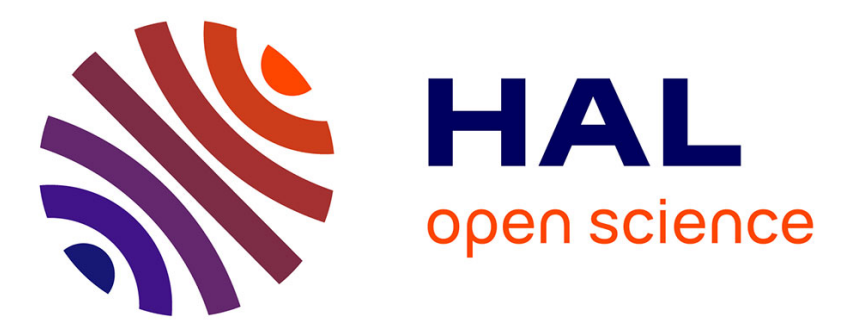

\title{
Nouvelles données sur les couvertures en plomb à Angkor
}

Christophe Pottier

\section{To cite this version:}

Christophe Pottier. Nouvelles données sur les couvertures en plomb à Angkor. Bulletin de l'Ecole française d'Extrême-Orient, 1997, 84 (1), pp.183-220. 10.3406/befeo.1997.2479 . halshs-01989484

\section{HAL Id: halshs-01989484 \\ https://shs.hal.science/halshs-01989484}

Submitted on 22 Jan 2019

HAL is a multi-disciplinary open access archive for the deposit and dissemination of scientific research documents, whether they are published or not. The documents may come from teaching and research institutions in France or abroad, or from public or private research centers.
L'archive ouverte pluridisciplinaire HAL, est destinée au dépôt et à la diffusion de documents scientifiques de niveau recherche, publiés ou non, émanant des établissements d'enseignement et de recherche français ou étrangers, des laboratoires publics ou privés.

\section{()ㅜ) $\Theta$}

Distributed under a Creative Commons Attribution - NoDerivatives| 4.0 International 


\section{Nouvelles données sur les couvertures en plomb à Angkor}

Christophe Pottier

\section{Citer ce document / Cite this document :}

Pottier Christophe. Nouvelles données sur les couvertures en plomb à Angkor. In: Bulletin de l'Ecole française d'ExtrêmeOrient. Tome 84, 1997. pp. 183-220;

doi : https://doi.org/10.3406/befeo.1997.2479

https://www.persee.fr/doc/befeo_0336-1519_1997_num_84_1_2479

Fichier pdf généré le 17/01/2019 


\title{
Nouvelles données sur les couvertures en plomb à Angkor
}

\author{
Christophe POTTIER
}

L'utilisation de tuiles en plomb à Angkor était suggérée depuis longtemps par le témoignage de Zhou Daguan qui, à la fin du XIIIe siècle, rapporte à propos du palais royal que « les tuiles de l'appartement principal sont en plomb ; sur les autres bâtiments du palais, ce sont toutes des tuiles d'argile, et jaunes »(Pelliot, 1951, p. 12). Mais aucun élément n'avait encore été retrouvé et ce type de couverture restait inédit à Angkor. À l'occasion des travaux de restauration du perron nord de la terrasse des Éléphants, des sondages réalisés de juin à septembre 1996 sur la face occidentale de ce perron ont mis au jour une importante quantité d'éléments de couverture en plomb ${ }^{1}$. Bien que les futurs travaux prévus dans la zone puissent encore permettre de dégager d'autres éléments de même nature, ceux d'ores et déjà collectés - plus de 80 objets et fragments - sont assez variés pour donner ci-dessous une première présentation des éléments de couverture en plomb. Suite à la description des divers éléments mis au jour, nous présenterons plusieurs réflexions relatives à la nature du métal utilisé, au procédé de fabrication et aux traces qu'a laissé sa métallurgie dans le Cambodge ancien, pour évoquer le problème lié à la provenance de ce métal. Puis, nous aborderons les éventuelles répercussions structurelles que ces éléments de couverture ont pu impliquer dans l'architecture, et chercherons leurs représentations éventuelles dans les architectures figurées à Angkor. Enfin, nous tenterons de dégager la provenance tant spatiale que chronologique des éléments découverts à la terrasse des Éléphants.

\section{Description des éléments de couverture}

Nous suivrons en partie la classification utilisée pour les tuiles de terre cuite par J. Dumarçay dans Charpentes et tuiles khmères : tuiles canal, couvre-joints, d'about, de coupes diverses et les épis de faîtage $\left(1973\right.$, p. 9) ${ }^{2}$. Nous préférerons cependant le terme

1. Cf. infra chronique p. 376-397. En parallèle aux travaux d'anastylose entrepris sur le mur du troisième état de la face orientale du perron nord, des fouilles ont été réalisées à l'ouest du même perron. La restauration de la face occidentale nécessitait en effet au préalable de connaître la configuration de cette zone qui n'avait jamais encore été dégagée. De juin à septembre 1996, huit tranchées de sondage (pl. 1) ont été ouvertes afin de suivre le plan du contrefort de latérite qui borde la face occidentale du perron, et de rechercher l'historique de son occupation. C'est à cette occasion que nous avons eu l'heureuse surprise de découvrir divers éléments de couverture en plomb.

2. Bien que la terminologie occidentale dénomme «tuile canal » indifféremment «toutes les tuiles à profil courbe formant sur le toit une série de rigoles parallèles, dans le sens de la pente " ( $L$ 'art de la couverture, 1982 , t. 2 , fasc. 4 , p. 157), nous conservons les termes de « canal » et « couvre-joints ». Ceux-ci sont assez imagés et évitent de recourir à une connotation romaine (tegula et imbrex [imbrice]) ou technique (courant et couvrant). 
« antéfixe » à celui de « tuile d'about », ce dernier se révélant relativement peu adapté aux éléments métalliques. Nous n'avons pas dégagé d'épis de faîtage et n'évoquerons donc pas cette catégorie, mais nous en ajouterons deux nouvelles, relatives aux tuiles plates et à des objets divers.

Les tuiles étaient réalisées dans un métal particulièrement malléable et facilement fusible. On ne saurait donc s'étonner de constater que les éléments dégagés présentent souvent des déformations importantes. Les restitutions des profils d'origine restent donc parfois hypothétiques. Enfin, le procédé de fabrication de ces éléments empêche d'accorder une valeur particulière à leur épaisseur. Notons donc que celle-ci varie de $2 \mathrm{~mm}$ à $5,5 \mathrm{~mm}^{3}$.

\section{Les tuiles canal}

Huit tuiles canal ont été collectées (tableau 1, photo 1). Leur configuration est très proche de celle des tuiles canal de terre cuite, hormis leur épaisseur plus fine. Leur poids oscille entre $1080 \mathrm{~g}$ et $2000 \mathrm{~g}$. Leur plan est trapézoïdal et la longueur varie de 267 à 310, pour une largeur de 240 à 190 en tête, et de 234 à 175 en bas. La plupart des tuiles canal ayant été retrouvées aplaties, la mesure de la largeur correspond à celle de la largeur développée. Pour la même raison, leur section reste incertaine dans la majorité des cas. Elles devaient avoir une coupe semi-rectangulaire aux angles arrondis et aux bords assez hauts (entre 35 et 50). La similitude de longueur avec les tuiles en terre cuite de type $B$ et $C$ ne se retrouve pas dans le constat de leur largeur. Bien que le nombre d'éléments recueillis soit réduit, deux tuiles semblent indiquer l'existence d'un type « large » aux bords hauts (plus de 240 en tête et de 225 en bas, bords supérieurs à 45) qui se distingue, indépendamment de la longueur, d'un second type plus étroit (moins de 215 en tête et de 195 en bas, pl. 2, n 35 ).

La barrette pour l'accrochage sur le lattis est souvent située aux $2 / 3$ de la longueur au dessus de la base. Un exemplaire montre une barrette située à la moitié, un autre aux 3/4. Faute de section évidente, il est délicat de calculer leur pureau. Pour indication, notons que si l'on applique à des tentatives de restitution la formule utilisée par J. Dumarçay pour les tuiles de terre cuite $(1973$, p. 10, note 2. Pottier, 1994, p. 298, note 4), les résultats varient de $1 / 2$ à $5 / 7$ (de 0,5 à 0,73 ).

\section{Les tuiles couvre-joints}

Six tuiles couvre-joints ont été dégagées (tableau 1, photo 2). De même que les tuiles canal, elles ressemblent à celles en terre cuite hormis l'épaisseur. Leur poids oscille de $1260 \mathrm{~g}$ à $1900 \mathrm{~g}$. Elles ont un plan trapézoïdal (longueur de 250 à 342, largeur en tête de 187 à 215 , largeur en bas de 210 à 235) et présentent un téton à l'intérieur. Elles devaient avoir une section demi-circulaire. Notons que deux exemplaires peuvent suggérer l'existence d'un type «long » (longueur supérieure à $335, \mathrm{pl} .3, \mathrm{n}^{\circ} 29$ ) face à un second type dont la longueur varie de 250 à 275 , semblable au type $B$ de terre cuite (pl. $3, \mathbf{n}^{\circ} 8$ ). Ce type «long » pourrait correspondre à des éléments de couverture d'arêtiers.

3. Sauf mention contraire, toutes les dimensions données dans ce texte sont en millimètre. La numérotation des éléments fait référence à l'inventaire des artefacts collectés et déposés à la Conservation d'Angkor. 
Le téton permet de caler ces tuiles les unes sur les autres. Le pureau coïncide donc à la distance du téton à la base (Dumarçay, 1973, p. 10). Le pureau observé est proche de $1 / 2$.

\section{Les antéfixes}

Comme nous l'évoquons plus haut, les « tuiles d'about » métalliques correspondent plutôt à des «antéfixes » ${ }^{4}$ : ces éléments ne sont constitués que d'un masque plat et d'une longue patte d'accroche qui file depuis le milieu de la base du masque sur une longueur variant de 168 à 238 (tableau 2). Plutôt qu'une réelle typologie, prématurée pour un corpus aussi réduit et original, la classification que nous avons établie se base sur les motifs des masques. Nous avons ainsi distingué neuf groupes d'antéfixes appelés ici «séries» (pl. 4 et 5). Chaque spécimen d'une série semble provenir d'un même moule tant les détails ou les imperfections sont identiques. Ces neufs séries correspondent donc, en fait, à neufs moules.

Lors de la découverte des premiers antéfixes, nous avions envisagé la possibilité d'y voir des éléments décoratifs du stupa qui domine le perron nord. Mais nous n'avons constaté aucune trace d'accroche correspondante sur les blocs de ce stupa - qui se révèle d'ailleurs être un réemploi d'un motif de couronnement d'une tour - et ces objets ont été trouvés dans une couche nettement antérieure à celle de la ruine de cette structure bouddhique. Enfin, même si certaines antéfixes ressemblent à des popils, objets rituels dont la présence est attestée dans le monde angkorien ${ }^{5}$, le nombre des éléments recueillis, la variété des masques et leur association à d'autres types de tuiles métalliques confirment bien leur rôle d'élément de couverture.

La différence de poids des antéfixes (de $500 \mathrm{~g}$ à $1200 \mathrm{~g}$ ) découle de l'inégalité de leur épaisseur plutôt que d'une différence particulière de taille. Lors de leur dégagement, les vingt-quatre exemplaires étaient sensiblement plats ou repliés sur euxmêmes, mais il est fort probable qu'un angle inférieur ou égal à $90^{\circ}$ ait à l'origine existé entre les plans du masque et de la patte d'accroche. Cette configuration a été observée sur certaines tuiles d'about en terre cuite du Prasat Thanon Hak (Pottier, 1994, p. 301). Plusieurs types de fixation semblent avoir été utilisés, peut-être sur un même édifice. L'élément pouvait être ancré directement sur la chanlatte : les antéfixes de la série I présentent une petite barrette en bout de patte qui peut avoir assuré l'accroche sur une latte (photo 4). Plusieurs exemplaires de la série A portent un trou circulaire sur la patte, près du masque. L'élément pourrait donc avoir été fixé par une cheville de bois ou une ligature. Ce système peut rappeler celui employé sur des tuiles plates retrouvées à Sambor Prei Kuk, à Angkor Borei et à Oc-éo (Malleret, 1959, p. 299. Dumarçay, 1973, p. 15 , note 5). Enfin, le seul exemplaire de la série $G$ à avoir conservé sa patte d'accroche $\left(n^{\circ} 54\right)$, présente sur toute la longueur de celle-ci des lignes croisées en relief qui, pouvant améliorer une adhérence au mortier, indiquent que la patte était engagée dans un solin de rive ${ }^{6}$. Le revers de chaque élément est plat, sans relief autre que quelques sur-épaisseurs liées au coulage. La base du masque est droite, sans encoche. Les motifs sont indiqués par un léger relief qui n'excède pas $3 \mathrm{~mm}$.

Les cinq premières séries forment autant de variations autour d'un motif commun : quatre ou cinq pétales de lotus à deux lobes stylisés et appuyés les uns sur les autres. Ce thème est couramment décliné sur les tuiles d'about de terre cuite (Dumarçay, 1973,

4. Nous suivons ici la terminologie utilisée dans $L$ 'art de la couverture (1982, t. 2, fasc. 4, p. 155).

5. Nous retrouvons par exemple la mention du don d'un popil dans l'inscription K. 240 dans la seconde moitié du $\mathrm{X}^{\mathrm{e}}$ siècle (Cœdès, 1951, p. 77, note 3 ).

6. Un fragment de patte d'accroche présente des rainures similaires $\left(n^{\circ} 63\right)$. 
p. 11-13, types de A à I, K et L). Mais ici, il est plus géométrisé et épuré, indiqué par de simples liserés sur un fond plat. La taille et la forme équilatérale convexe - ou en ogive - de leur masque sont sensiblement constantes : hauteur d'environ 120, largeur de 110. Le masque a sa base encadrée par deux petites extensions triangulaires recourbées en volute vers le haut.

I-4a Série A : Le masque, retrouvé en six exemplaires, présente cinq pétales superposés qui suivent le contour ogival du masque. L'axe vertical qui sépare les deux lobes de chaque pétale est continu et fortement marqué. Les deux pétales supérieurs reposent sur un petit bandeau horizontal qui disparaît sous les trois pétales inférieurs. La base de ceux-ci s'amortit sur celle du masque pour se redresser dans les volutes latérales.

I-4b Série B : Un seul exemplaire a été mis au jour (photo 3, en bas à droite). Nous y observons cinq pétales superposés : le premier repose sur un double bandeau, les deux suivants rejoignent la base du masque sans s'y retourner, le troisième et le quatrième sont bordés de flammèches stylisées. L'axe médian du masque est aussi marqué que dans la série $\mathrm{A}$.

I-4c Série $\mathrm{C}$ : Six exemplaires ont été dégagés. Le masque tend vers une ogive surhaussée, forme isocèle aigue plus élancée que les séries précédentes mais avec l'axe médian aussi nettement marqué. Le masque comporte quatre pétales superposés. Un bandeau rythmé de segments verticaux souligne la base du masque sur toute la largeur, hormis au centre où il est recouvert par la base du premier pétale en relief, étroit et haut. Le second pétale est encadré de flammèches réduites à des segments linéaires qui rejoignent le pétale inférieur. Les extensions latérales prennent leur départ sous le bandeau et se retournent vers le haut, scandées de la même manière que le bandeau. Notons que la patte d'accroche de ces antéfixes est particulièrement étroite (environ 25).

I-4d Série D : Les masques des cinq exemplaires de cette série présentent quatre pétales superposés, sans indication de l'axe médian vertical, reposant sur un liseré horizontal retourné vers le haut dans les extrémités latérales. Les pétales sont stylisés et seul leurs contours triangulaires sont indiqués, sans axe médian. Leurs profils évoluent du triangle équilatéral aux bords rectilignes pour le premier, au triangle isocèle convexe légèrement aigu pour le dernier. Le deuxième et le troisième pétales sont encadrés de flammèches semblables à la série précédente, qui se prolongent d'un pétale à l'autre, donnant ainsi un effet rayonnant.

I-4e Série E : Stylisé à l'extrême, sans mention d'axe vertical médian, le masque de l'unique exemplaire porte au centre de sa base un arc légèrement aplati qui semble se rattacher à un arc trilobé situé au dessus, lui-même dominé par un forme en léger relief peu lisible et vaguement circulaire (photo 3, à droite). L'ensemble est encadré par trois pétales réduits à leur contour en ogive. Les deux premiers pétales présentent une composition de flammèches identique à celle de la série précédente. Le motif de ce masque présente une certaine analogie avec celui que présente un popil publié par $S$. Thierry (1984, p. 76-77); l'auteur écrit à son sujet qu'il semble « ancien et d'un décor rare aujourd'hui. L'interprétation de celui-ci n'est pas claire. L'étagement des motifs fait penser aux parasols royaux, ou aux Trois Mondes. Mais il se pourrait que ce popil soit un «popil sima», évoquant les bornes rituelles ou «feuilles de sima » qui délimitent les enceintes de temple».

I-4f Série F : Un seul exemplaire a été retrouvé (photo 3, en haut à droite). Le masque est en forme d'écu renversé. Au centre, une forme en relief oblongue à la base effilée repose sur un piédestal à deux gradins scandés par des segments verticaux. La partie supérieure étant lacunaire, il n'est malheureusement pas possible de connaître le sommet de cette forme qui est encadrée par une superposition de quatre pétales stylisés dont seul le profil en bulbe est indiqué par un liseré. Le second pétale et la partie basse 
du suivant présentent sur leur contour des segments rayonnants figurant des flammèches qui se poursuivent jusqu'au extensions latérales bien prononcées. Celles-ci, comme celles de la série $C$, sortent de la base du masque pour remonter vers l'extérieur.

I-4g Série G : L'antéfixe, dont la forme est identique à la série précédente, représente les têtes d'un naga pentacéphale sous une arcature flammée. Bien que ce thème ait déjà été retrouvé sur des masques en terre cuite (Dumarçay, 1973, type $R$, p. 14, Fig. 48. Pottier, 1994, type V, p. 301, pl. VII), la composition est ici nettement différente. Le bas du naga rejoint deux arcs de cercle concentriques qui reposent sur un bandeau courbé au centre et dont les extrémités flammées se redressent en volute. Deux exemplaires de cette série ont été retrouvés (photo 3, à gauche).

I-4h Série H : Le masque de l'unique exemplaire représente une orante, de face, les mains jointes sur la poitrine (photo 3 , au centre). Ce motif se retrouve, avec de nombreuses variations de détail, sur diverses tuiles d'about en terre cuite (Dumarçay, 1973, types $M, N$ et $P$, p. 13-14, fig. 44, 45 et 47 ) et sur de nombreux masques de popils (Thierry, 1984). Sur le visage que présente l'exemplaire métallique, sont clairement indiqués les yeux, le nez, les deux lèvres et les reliefs du menton, des pommettes et du front. L'orante porte sur la tête un diadème pointu des cotés duquel pendent deux guirlandes qui se redressent en volute au niveau des épaules. Elle est parée de trois colliers et de deux brassards près de chaque épaule. Le torse nu, les seins nettement dessinés, elle porte une ceinture qui maintient une jupe au niveau des hanches et qui descend devant en dégageant le ventre. La ceinture et la jupe sont rythmées par des petits segments qui semblent indiquer un motif. L'orante est représentée sous une arcature pentalobée flammée, qui se retourne en volute vers l'extérieur à la base du masque. Le contour du masque suit fidèlement cette forme polylobée. Notons que ce masque est l'un des rares exemples (avec la série G, mais dans une moindre mesure) à traduire un souci d'expression des formes par un jeu de légers reliefs, et non pas par le soulignement des contours à l'aide de liserés.

I-4i Série I : La dernière série, dont trois exemplaires ont été retrouvés, a la forme d'un bouton de lotus reposant sur un bandeau horizontal recourbé vers le haut aux extrémités (photo 4). Ce bandeau est rythmé par des segments verticaux ou obliques dessinant des rectangles et des triangles isocèles. Des segments rectilignes semblables ornent la partie centrale du masque encadrée dans une arcature trilobée. Ils y déterminent une composition géométrique à base de triangles quasi équilatéraux, superposés en alternance sur quatre registres de hauteur décroissante vers le sommet. Le triangle central du troisième registre, situé au centre du masque, présente une surface nettement en relief qui semble être le motif principal. Coulés dans le même moule, les trois exemplaires présentent dans leur partie supérieure les mêmes défauts de fabrication qui empêchent de lire distinctement les motifs du sommet de cette partie centrale. Il est à peine possible d'y discerner l'amorce de deux triangles isocèles symétriques reposant sur le quatrième registre. Ces triangles semblent indiquer des ogives encadrant deux motifs en relief. Du liseré qui délimite l'arcature trilobée rayonnent des flammèches rectilignes qui rejoignent la bordure cordiforme du masque. Remarquons que cet aspect cordiforme présente quelques analogies avec ceux de divers popils en forme de figuier «pipal » (ficus religiosa) ou de bétel (piper betel) (Thierry, 1984 , p. 1). Enfin, seuls les exemplaires de cette série présentent en bout de patte d'accroche une barrette destinée à se bloquer sur la chanlatte.

\section{Les tuiles plates}

Seuls de rares fragments plats en terre cuite, de date et de provenance indéterminées, suggèrent l'existence de couverture avec des tuiles plates à Angkor. 
Parmi les éléments métalliques, un seul exemplaire complet de tuile plate a été retrouvé ( ${ }^{\circ} 13$, tableau 3, pl. 6). L'élément est déformé et en partie replié sur lui-même mais sa forme d'origine ne laisse guère de doute. Il atteste donc de la présence d'un type de couverture très particulier. Son plan, remis à plat, montrerait une feuille en losange asymétrique, haut de 334 et large de 236. Alors que trois angles sont vifs et obtus $\left(97^{\circ}\right)$, un seul est aigu et légèrement arrondi. Ce dernier restant grossier, il pouvait être situé en tête et recouvert par la pointe de base de la tuile supérieure. Il est aussi probable qu'un léger recouvrement latéral ait pu exister, ce qui expliquerait la dissymétrie constatée. Le pureau aurait alors une forme presque carrée. Un téton de fixation est situé près du centre, à 160 de l'angle de base. L'épaisseur de la feuille métallique est environ de 3,2 sur ses bords.

\section{Les tuiles de coupes diverses}

Parmi les éléments courbes, seule une tuile couvre-joints $\left(\mathrm{n}^{\circ} 8\right.$, tableau 1, pl. 3 , photo 2 à gauche) présente l'angle gauche de son chef de base tronqué. Cette particularité ne semblant pas accidentelle, il est probable que cet élément ait été situé à droite d'une noue?

De nombreux éléments présentent des coupes particulières (tableau 3). Mais, ayant été retrouvés aplatis, sans trace de téton ou de barrette, et portant des traces de coupe réalisées au ciseau, le caractère hypothétique de toute interprétation fonctionnelle doit être souligné. Notons tout d'abord deux éléments de plan rectangulaire. L'un est plié en deux $\left(\mathrm{n}^{\circ} 51\right.$, dimensions : $225 \times 152 \mathrm{~cm}$ ) et sa fonction reste inconnue. L'autre, plat, présente sur une face longue une petite extension $\left(n^{\circ} 44\right.$, dimensions : $215 \times 100 \mathrm{~cm}$, pl. 2). Il porte des traces de fonte qui montrent que l'extension était prévue dès le coulage. Le bout de cette extension étant coupé, celle-ci peut donc avoir été plus longue à l'origine. Cet élément pourrait être une tuile canal de tête dont l'extension devait servir à l'ancrage dans l'embarrure. Cette tuile permettait de réduire la surface de mortier exposée et d'augmenter ainsi l'étanchéité au faîtage.

Un dizaine d'éléments plats ont un plan en triangle rectangle. Il est probable que certains ne soient que des fragments découpés dans des tuiles plates, canal ou couvrejoints car tous montrent sur les petits côtés des arêtes nettes de coulage, alors que leur long côté provient d'une troncature. Ces éléments trouveraient place dans une toiture couverte de tuiles plates à pureau en losange, et y seraient placés dans les interstices laissés par les éléments losanges, en raccord sur un pignon ou un arêtier. Ils seraient fixés par adhérence à une ruellée ou par engagement dans le mortier de l'arêtier. Par contre, une pièce $\left(n^{\circ} 47\right)$ possède les mêmes caractéristiques mais avec son petit coté légèrement relevé. Si, comme nous le pensons, cette forme est d'origine, cet élément aurait la même fonction qu'un autre élément de forme trapézoïdale qui, lui, a ses deux petits cotés recourbés ( $n^{\circ} 96$, photo 2 en bas à gauche). Ces deux éléments seraient des

7. Il est tentant de calculer la pente de la toiture à partir de l'angle de la troncature en utilisant la formule suivante: soit a l'angle recherché pour la pente, b l'angle de la troncature avec l'axe de l'élément et $\mathrm{c}$ celui de la noue en plan, $\mathrm{a}=\arccos (\tan \mathrm{b} / \tan \mathrm{c})$. Pour une noue à $45^{\circ}$ en plan, $\tan \mathrm{c}=1$. La tuile étant déformée et l'angle de la troncature imparfaitement linéaire, ce dernier a été estimé entre $38^{\circ}$ et $41^{\circ}$ par rapport à l'axe de la tuile. Cette imprécision donne des résultats assez généraux : respectivement de $38,6^{\circ}$ et $29,6^{\circ}$. Cela impliquerait que cette tuile provienne d'une noue de brisis ou d'un appentis. Mais, sans tenir compte de l'imprécision liée à l'objet lui-même et à sa fabrication, ce calcul se fonde sur une hypothèse loin d'être évidente, à savoir que l'angle de la troncature correspond parfaitement à celui de la noue. Des essais de calcul réalisés à partir des tuiles de noues présentées par J. Dumarçay (1973, fig. 50 et fig. 51) nous mènent en effet à des impasses, à moins de concevoir des noues autres qu'à $45^{\circ}$. 
tuiles canal tronquées pour être placées à droite d'une noue. L'absence de barrette de fixation indiquerait qu'elles étaient fixées au mortier et coincées dans la tête de la tuile canal inférieure ${ }^{8}$.

\section{Éléments divers}

Plusieurs fragments métalliques se présentent sous la forme d'un tuyau (tableau 3 ). Certains sont parfaitement cylindriques. Composés d'une feuille métallique rabattue sur elle-même dans son sens longitudinal, il est improbable que ces éléments soient des pattes d'accroche d'antéfixes déformées fortuitement de cette manière. D'ailleurs, un exemplaire $\left(n^{\circ} 81\right)$ présente une longueur nettement supérieure à celle des pattes d'accroche. Il semble donc plutôt que leur forme actuelle correspond à celle d'origine. Le diamètre de ces éléments est légèrement supérieur à 20 pour une épaisseur de 2,5 . Il reste délicat de déterminer leur fonction : éléments de couverture ou de plomberie ? Dans le premier cas, ils pourraient constituer des tenons de fixation, pour des épis de faîtage par exemple. Dans le second, plus probable si l'on considère le contexte où ils ont été retrouvés (cf. infra, p. 206-208), ils confirment l'existence de réseaux de plomberie déjà mis en évidence par des éléments du même type, en cuivre au Mebon occidental (Dumarçay, 1982, p. 102), et en plomb à Sra Srang (Courbin, 1988, p. 2325).

\section{Les couvertures en plomb}

La découverte de ces éléments de couverture en plomb suscite quelques interrogations sur le matériau lui-même et le procédé de fabrication utilisé. Elle offre aussi l'occasion de dégager certains aspects de la métallurgie de ce métal dans le monde khmer, sa provenance et les éventuelles répercussions architecturales de son utilisation à des fins de couverture.

\section{Plomb ou étain?}

Le matériau utilisé pour ces éléments de couverture est gris, recouvert d'une pellicule oxydée blanchâtre inégalement épaisse ${ }^{9}$, malléable et cassant sans être mou. Sans doute influencés par les tuiles de plomb mentionnées par Zhou Daguan, nous avons bien sûr associé ces éléments à du plomb. Leur aspect correspond à ce métal, mais la densité relevée pour les éléments complets varie de 6 à 10 et ne coïncide pas à celle du plomb - 11,35. Elle se rapproche par contre de celle de l'étain - 7,29 - avec lequel elle montre une meilleure adéquation. D'aspects assez proches, nous noterons, à

8. L'élément $\mathrm{n}^{\circ} 25$ pourrait être du même type mais sa déformation plus importante laisse douter de la présence d'un côté relevé.

9. Plusieurs exemplaires portent sur cette surface blanchâtre une fine couche orange rouge. Ces objets ayant été dégagés dans des couches à haute densité latéritique, il nous semble que cette coloration soit accidentelle et ne constitue pas la trace d'une couverte colorée. 
la suite de L. Malleret (1960, p. 270 , note 1), que le plomb et l'étain sont assez faciles à confondre ${ }^{10}$.

$P$. Pelliot suggère d'ailleurs que Zhou Daguan a fait cette confusion : « malgré la précision du mot employé par Tcheou Ta-kouan ( $k$ 'ien, « plomb »), peut-être ne s'agit-il pas vraiment de plomb. M. Groslier a déjà remarqué qu'à la fin du XVIIe siècle, Gervaise signale à Ayuthia des couvertures en étain. La Loubère est non moins précis: «Au reste ils ne connoissent nul ornement extérieur pour les Palais, ny pour les temples, que dans les combles qu'ils couvrent ou de cet étain bas qu'ils nomment Calin, ou de tuiles vernies de jaune, comme il y en a au Palais du Roy de la Chine. » (...) Il y a eu une telle similitude entre les habitudes siamoises et cambodgiennes que je ne suis pas éloigné de penser qu'il s'agit dans les deux cas du même produit » (1951, p. 146-147, note 1). Nous n'avons pas trouvé trace de ce calin au Cambodge. Par contre, le monde insulindien en a gardé la mémoire. Le calin se retrouve au début du siècle suivant chez les Chinois de Batavia qui excellaient dans sa fabrication : D. Lombard rappelle à ce propos que F. Valentijn décrit cette « sorte de métal appelé calin qui diffère peu de l'argent (dont) il a à peu près la même apparence (...), coûte un quart en moins et est très beau » (Lombard, 1990, t. II, p. 229-230). Dérivant du terme malais kaleng, ce calin semble en fait correspondre à un alliage principalement à base d'étain, contenant peutêtre du plomb ". Par ailleurs, l'étain était aussi utilisé au début du XVIIe siècle sous forme de tuiles plates pour la couverture qui « rappelait les écailles d'un naga » d'un pavillon situé dans les jardins du palais du sultanat d'Aceh (Lombard, 1967, p. 133). Mais il n'est guère possible, faute de renseignements plus précis, de voir dans les couvertures des palais d'Angkor, d'Aceh et d'Ayuthia un seul et même alliage. Si dans l'avenir des échantillons devaient être retrouvés pour chacun de ces sites, une recherche plus poussée permettrait alors de préciser ces comparaisons et, peut-être, de mettre en évidence le rôle éventuellement joué par la communauté chinoise dans sa fabrication ou dans sa fourniture : à Aceh, proche de Batavia où elle est parfaitement attestée, à Ayuthia où les artisans chinois sont à moult reprises mentionnés (Hanks et M., 1988), ou encore au Cambodge (cf. infra p. 199-200). Mais nous soulignerons au moins ici l'analogie avec Ayuthia qui a reçu du monde angkorien une très forte influence dans de nombreux domaines (Groslier, 1983, p. 214-220), dont la métallurgie, en particulier celle du bronze (Boisselier, 1967, p. 280-282). Les éléments de couverture dégagés à la terrasse des Éléphants peuvent alors apparaître comme les prototypes des toitures des édifices palatiaux siamois. Plomb ou étain, un doute pourrait donc subsister quant à la nature exacte de l'alliage utilisé.

L'ambiguiité entre ces deux métaux entraînant par ailleurs des répercussions importantes pour la conservation des éléments retrouvés, nous avons confié quatre échantillons pour analyses ${ }^{12}$. Seuls ont pu être réalisés des tests par attaques chimiques qui ne permettent que de relever les métaux en quantité importante. Ni la présence de métaux en faible proportion ni les proportions de ceux-ci n'ont pu être déterminés. Tous

10. Signalons au passage que la langue khmère contemporaine ne possède pas de terminologie très différenciée pour ces deux métaux : sâmnor pour le plomb en général, sâmnor phok pour le plomb « pur » (litt. :plomb en boue), et... sâmnor pa haing pour l'étain (litt. : alliage de plomb). De même en français, l'origine latine du mot étain, stagnum, dérivé de stannum, ne signifie rien d'autre que «plomb argentifère »!

11. Désignant en indonésien moderne le «fer blanc» et les «boîtes de conserves », le calin semble avoir gardé son sens d'origine puisque les boîtes de conserves sont constituées habituellement d'un alliage $\mathrm{Sn} 75 \%$ et $\mathrm{Pb} 25 \%$ (bien que l'aluminium le détrône actuellement). Nous remercions D. Lombard pour les renseignements qu'il a bien voulu nous communiquer sur l'étymologie et l'emploi de ce terme.

12. Ces analyses ont été réalisées à l'Institut de Technologie du Cambodge à Phnom Penh. Nous remercions $\mathrm{P}$. Sackona et $\mathrm{P}$. Fonkenell pour l'aide qu'ils ont bien voulu nous apporter. 
les échantillons ont mis en évidence du plomb, mais la faible masse volumique de certains éléments indique pourtant la présence d'autres composants, sans qu'il ait été possible à ce stade d'analyse de les identifier. Nous considérerons donc dans le doute qu'il s'agit d'un alliage à teneur élevée en plomb. L'utilisation de ce métal pour des couvertures architecturales ne saurait d'ailleurs surprendre : l'oxydation à l'air développant en surface un carbonate basique protecteur, ce métal fut employé dans cette fonction dans plusieurs régions du monde et à des époques diverses.

\section{Fabrication des éléments de couverture}

L'observation des divers éléments retrouvés apporte quelques renseignements d'ordre technologique. La technique de fonte à la cire perdue, employée tant pour les bronzes (Boisselier, 1967, p. 278) que pour les popils (Thierry, 1984, p. 6), n'a pas servit pour la fabrication des éléments de couverture. De même, la fonte dans des moules bivalves, technique attestée à Angkor par les quelques spécimens en grès, en schiste ou en phtanite retrouvés (Malleret, 1960, p. 288), ne semble pas non plus avoir été employée ici. En fait, les traces que présentent les objets montrent des marques évidentes de coulage sur un moule plat : bavure de fonte (photo 3 ), empreinte de bords de moule (photo 2), manque ponctuel de matière, différence d'épaisseur sur un même élément, imperfection des motifs des antéfixes sur tous les exemplaires de même série, surcharge ponctuelle de fonte au revers... Bien qu'aucun moule correspondant n'ait été retrouvé, leur utilisation semble ici certaine et il est fort probable que les profils définitifs des tuiles canal, couvre-joints ou des antéfixes aient été simplement obtenus après solidification, la malléabilité du matériau le permettant aisément. Nous avons relevé l'épaisseur de chaque élément. Celle-ci n'a qu'une valeur indicative et un intérêt relativement limité puisque cette épaisseur est extrêmement aléatoire, en fonction de la main plus ou moins généreuse du fondeur, le poids des éléments variant du simple au double pour le même type d'objet. Il est aussi envisageable que certaines parties aient pu être soudées, éventuellement avec un alliage mixte étain / plomb, fusible à faible température (téton de l'exemplaire $n^{\circ} 98$ rajouté sur une barrette de tuile canal, photo 2 à droite).

Notons aussi que certains éléments présentant des troncatures ont pu être retaillés ou coupés ultérieurement à la demande lors de la pose, à moins que ces traces n'indiquent une réutilisation. Nous avons noté plus haut que les tuiles métalliques ont été retrouvées aplaties ou avec des déformations parfois importantes. Outre la pression des terres sous lesquelles elles furent ensevelies, certaines déformations peuvent être dues à une surchauffe, voire à un incendie (photo 1 en haut à gauche) ${ }^{13}$, mais nous ne saurions cependant en déduire que la totalité des éléments retrouvés ont subi un tel sort ${ }^{14}$. Alors que ces tuiles se prêtent aisément à la réutilisation, les traces de découpe observées sur plusieurs spécimens dégagés permettent surtout d'envisager avoir affaire à un stock de plomb récupéré en voie d'être fondu à nouveau - ce qui expliquerait la présence de tuyauteries et la grande variété des types d'objets en plomb. Nous verrons plus bas qu'il est même possible de soupçonner la présence d'un atelier métallurgique dans la zone à

13. Le plomb étant facilement fusible $\left(327,5^{\circ} \mathrm{C}\right)$, l'incendie d'un bâtiment peut atteindre des températures nettement supérieures à son point de fusion.

14. La plupart des éléments de plomb ont été dégagés dans un environnement présentant une importante quantité des charbons et de fragments de tuiles de pâte jaune sans couverte ou grise à glaçure verte. La couleur grise de certaines de ces tuiles de terre cuite pourraient en effet indiquer la trace d'un incendie. Cf. l'étude de C. Kiefer sur un masque de tuile d'about du palais royal d'Angkor Thom (Dumarçay, 1973, p. 72). 
un niveau associé à celui où ont été mis au jour certains éléments de couverture. Incendie et/ou rassemblement en vue d'une réutilisation, il reste que la rareté des tuiles en plomb mises au jour semble indiquer que la métallurgie de ce métal fut peu développée à Angkor.

\section{Présence d'une métallurgie du plomb}

Il semble donc nécessaire de replacer ces tuiles de plomb dans le cadre plus général de la métallurgie de ce métal - auquel nous adjoindrons l'étain, souvent confondu et parfois associé, et ponctuellement l'argent dont la production est étroitement associée dans l'exploitation des galènes argentifères. Alors que l'or et surtout le bronze ont fait l'objet d'études spécifiques, favorisées par le nombre et le caractère artistique des pièces réalisées en ces métaux, le plomb n'a souvent été mentionné que sommairement, au fil d'études diverses. Nous résumerons donc ici les traces que cette métallurgie a laissé dans le monde angkorien.

Précisons préalablement que l'origine d'une métallurgie du plomb au Cambodge reste encore inconnue. On constate certes la présence de plomb dans certains bronzes protohistoriques de Mlu Prei (Levy, 1943, p. 38) ou de la civilisation chalcothique de Dông-son retrouvés au Cambodge (Bezacier, 1972, p. 281-289). Mais, soit que le plomb n'y dépasse pas la proportion d'impureté, soit que leur provenance exacte reste indéterminée (Boisselier, 1966, p. 31-32), ces indications ne permettent pas de conclure à l'existence d'une métallurgie au Cambodge avant la période historique. Au début de celle-ci, alors que le plomb « a été l'objet dans l'Inde d'une très ancienne métallurgie » (Malleret, 1960, p. 271), c'est encore dans les franges de la métallurgie du bronze, mais surtout de celle de l'étain découverte à Oc-éo par L. Malleret, que l'on trouve une première utilisation réduite mais délibérée du plomb dans la région. Les recherches d'Oc-éo ont révélé l'emploi de l'argent et de l'étain, ce dernier à tel point que cette civilisation de l'étain « paraît être la caractéristique essentielle du site » (Malleret, 1960, p. 265-350. Boisselier, 1966, p. 34) et marque le début de la période founanaise. Ces travaux offrent aussi indirectement un jalon pour le plomb qui s'y retrouve soit comme constituant principal, soit en alliage dans le bronze - dans des proportions non résiduelles qui dépassent parfois même celle de l'étain ${ }^{15}$ - soit encore dans des objets d'étain (Malleret, 1960, p. 358-367 et 371-377). Parmi ces derniers, la grande majorité ne présente que des traces de plomb qui proviendraient du procédé de réduction rudimentaire utilisé pour l'étain (Malleret, 1960, p. 372). Cependant, diverses pièces semblent comporter une proportion non fortuite - bien que seul un exemplaire analysé montre un alliage $\mathrm{Sn} 70,5 \% / \mathrm{Pb} 28,5 \%$. Enfin, quelques objets, dont une quantité importante d' " anneaux alourdis », sont principalement ou totalement composés de plomb. L. Malleret rappelle d'ailleurs la similitude de forme qu'offrent ces anneaux alourdis d'Oc-éo avec ceux représentés sur la poitrine de nombreuses devata d'Angkor Vat ou attestés par quelques moules bivalves trouvés à Angkor (Malleret, 1960, p. 288 et 309).

Dans le monde khmer, alors que les mentions directes du plomb et de l'étain sont rares, leur utilisation y est pourtant assurée. Nulle métallurgie de l'importance de celle

15. L. Malleret souligne la difficulté d'utilisation des analyses chimiques des bronzes à des fins archéologiques. Mais dans le cas présent, tout en considérant l'extrême variation de composition des alliages à l'intérieur d'un même objet, il reste que les pourcentages de plomb montrent que ce métal était connu et utilisé. Il semble par contre improbable de voir dans les objets d'argent d'Oc-éo un indice en vue d'une métallurgie du plomb. En effet, les analyses réalisées ont montré des traces trop ténues de plomb pour « indiquer une galène pour la provenance » de l'argent (Malleret, 1962, p. 461). 
d'Oc-éo n'a laissé de témoin dans le monde khmer si ce n'est celle du bronze. C'est d'ailleurs encore en partie par le bronze que se signalent la présence de l'étain et celle résiduelle du plomb ${ }^{16}$. Les objets d'étain retrouvés à l'occasion des dégagements ou des fouilles sont exceptionnels. P. Courbin mentionne sans précision de forme que « de l'étain a été recueilli, notamment dans un vase funéraire " dans la première nécropole de Sra Srang (seconde moitié du XIe siècle) fouillée en 1963 sous la direction de B. P. Groslier (Courbin, 1988, p. 23) ${ }^{17}$. D'autre part, les rapports de la Conservation d'Angkor, de 1908 à 1973, n'offrent qu'une seule mention de l'étain ! Encore n'est-elle pas assurée : M. Glaize y indique prudemment en octobre 1940, à la fin de sa rubrique divers, « deux petites plaquettes en alliage paraissant à base de plomb ou d'étain, ornées d'un buddha assis ». La confusion de l'étain et du plomb étant envisageable en l'absence d'analyses, nous pourrions espérer retrouver des mentions plus fréquentes de ce second métal. Mais les indications d'objets en plomb sont presque aussi rares et se résument à quelques débris informes, des saumons (lingots hémisphériques) et un petit bouddha grossier ${ }^{18}$. Les fouilles de Sra Srang ont aussi mis au jour plusieurs objets en plomb associés à des dépôts funéraires de la première nécropole : des saumons, des petits lingots en forme de pyramide tronquée, des anneaux, des tuyaux écrasés et « du plomb ouvragé » (Courbin, 1988, p. 23-24).

L'épigraphie nous fournit quelques indications complémentaires: bien que peu prolixes en mentions de plomb ou d'étain, les inscriptions indiquent en de rares occasions des lingots, des récipients, des gobelets ou des vases en ces métaux ${ }^{19}$. Ceuxci y sont dénombrés l'un à la suite de l'autre dans des listes d'offrandes. P. Cordier relève d'ailleurs une mention possible d'un alliage étain/plomb et souligne la confusion possible entre ces deux métaux (K. 273, st. CXVI, Cœdès, 1992, p. 51). Outre que ces deux métaux sont parfois associés dans les textes lapidaires, ils sont souvent

16. Le plomb peut apparaître dans certains bronzes angkoriens dans proportions importantes. Les analyses réalisées récemment sur plusieurs bronzes du musée de Phnom Penh confirment cette présence du plomb - jusqu'à $22 \%$ - et suggèrent une utilisation délibérée (T. Zéphir, « À propos de quelques bronzes conservés au Musée national de Phnom Penh », communication au colloque organisé par l'A.F.A.O. «Connaissance de la sculpture khmère, aspects historiques et esthétiques », 11 mars 1997, Grand Palais, Paris).

17. Contra : «M. Groslier m'a dit qu'on n'a pas trouvé d'objets d'étain dans les fouilles archéologiques d'Angkor » (Yang, 1994, p. 231, note 3).

18. Novembre 1917, Phimeanakas : «(..) dans les déblais de menus débris métalliques sans importance de petits morceaux de plomb». Mars 1922, palais royal: «On a trouvé dans le dégagement du perron intérieur Sud deux saumons de plomb en forme de calotte sphérique $0.20 \mathrm{~m}$ de diamètre et de $0.07 \mathrm{~m}$ d'épaisseur ». Mars 1923, Bapuon : «Les fouilles dans l'angle du perron Nord ont montré des traces charbonneuses très nettes mélangées à de nombreux fragments de tuiles en terre cuite et des débris de poteries. (...) On a également trouvé de petits morceaux de plomb dans le déblais ». Juillet 1925, Bakheng : «Vestiges au Sud-Ouest du Bakheng. (...) On a trouvé vers le milieu de l'emplacement un petit buddha assis en plomb très grossier de facture de $6 \mathrm{~cm}$ de hauteur ». Août 1941, Bakong : «Nous avons terminé (...) le dégagement intérieur du bâtiment en longueur Sud de la face Est, compris la petite pièce formant avant-corps à l'extrémité Ouest (...). Nous avons trouvé au cours des fouilles quelques morceaux de plomb enrobés de mortier : aucune déduction ne peut être tirée de leurs formes respectives ». Janvier 1943, Mebon occidental : «Dégagements des tours médiane et Sud de la face Est (...). Quelques débris de poteries et fragments de plomb enrobés de mortier ont été trouvés dans les déblais ». Octobre 1944, Angkor Thom: «Parmi quelques trouvailles sans intérêt faites par des indigènes dans la brousse d'Angkor Thom, nous ne voyons guère à signaler qu'une galette circulaire en plomb (diamètre $0.15 \mathrm{~m}$ ) du poids de $3.200 \mathrm{~kg}$ ». Un fragment de saumon a été mis au jour en janvier 1995 dans le remblai de la Terrasse du Roi Lépreux.

19. L'examen exhaustif de toutes les sources épigraphiques dépasserait ici notre sujet. Nous noterons donc seulement quelques exemples tirés d'une simple lecture des traductions de G. Cœdès : K. 235 (1992, p. 212), K. 258 (1952, p. 194 et 200-201), K. 273 (1992, p. 44-45), K. 908 (1992, p. 158,163$)$. 
notés après les présents en or, en argent en bronze ou en cuivre. Ceci semble être l'indice d'une position basse dans l'échelle de valeur des métaux, en queue pourrait-on dire, avant de passer à la catégorie des récipients de terre cuite. C'est aussi ce que suggère le récit de Zhou Daguan, qui rapporte l'utilisation de gobelets à vin et de bols rince-doigts en «alliage blanc »-d'étain et de plomb ou de cuivre (Yang, 1994, p. 231, note 3) - dans les milieux aisés, les plus favorisés utilisant de l'argent ou de l'or, les plus modestes se contentant d'écuelles de terre (Pelliot, 1951, p. 31). Cette valeur relativement faible du plomb ou de l'étain, face à des métaux précieux, pourrait d'ailleurs expliquer en partie leur rareté dans les inscriptions. Cependant, les objets de plomb découverts à Angkor depuis le début du siècle demeurent exceptionnels, même si ce constat doit être relativisé en soulignant que peu de fouilles ont été réalisés hors d'un contexte monumental. Il reste néanmoins que la fréquence des objets de plomb est sans commune mesure avec celle des objets de bronze.

Notre récolte de plomb serait donc bien maigre si nous nous cantonnons aux objets non architecturaux ${ }^{20}$. Outre quelques rares dépôts de fondation présentant des objets de plomb ${ }^{21}$, c'est surtout dans la construction de temples que la présence de ce métal est la plus fréquemment attestée par de nombreux scellements au plomb, tant pour les crampons que pour les crapaudines des portes. Nous n'avons pas trouvé trace de cette technique de scellement durant le période pré-angkorienne. Â notre connaissance, et pour les crampons, cette technique semble apparaître, du moins se développer, avec le parement de grès durant, ou peu avant, le règne d'Indravarman Ier. Largement utilisée durant la période angkorienne, nombreux en sont les témoins tant à Angkor que dans les temples provinciaux. Les scellements se font cependant plus rares avec l'emploi de plus en plus clairsemé de crampons et nous en perdons la trace avec l'abandon de l'édification de sanctuaires de grès après le XIIIe siècle, faute de monument pour attester de leur présence. La coïncidence avec les tuiles de plomb, moins courantes mais elles aussi destinées à un certain type de construction, suggère un emploi du plomb souvent associé à l'architecture. Il semble donc que dans le monde khmer, alors que les mentions directes du plomb et de l'étain sont rares, leur utilisation y est pourtant assurée. La métallurgie du plomb apparaît alors, au vu des vestiges et des mentions conservés tout au moins, comme liée à une production vraisemblablement réduite d'objets usuels - et de poids ?- et à un aspect utilitaire lié au domaine de la construction monumentale.

La méconnaissance de la période post-angkorienne ne permet guère de suivre précisément cette métallurgie et, ici encore, sa présence résiduelle se signale à travers celle du bronze (Giteau, 1975, p. 26-27). Nous pouvons néanmoins suggérer que, quantitativement au moins, l'emploi de ce métal a du être fortement réduit avec l'appauvrissement du pays khmer et l'abandon de l'édification de temples en pierre, et donc des scellements. À ce propos, la recherche et l'arrachement des crampons angkoriens - et de leurs scellements ? - qui ont touché de nombreux temples à une période indéterminée, peuvent être interprétés à la fois comme l'indice du déclin de l'activité métallurgique et comme une confirmation indirecte de sa permanence si toutefois les auteurs de cette récupération étaient cambodgiens. Les traces de l'emploi du plomb se retrouvent à l'aube du XVIe siècle où Duarte Barbosa, un voyageur

20. Notons encore qu'il est envisageable que des oxydes de plomb aient été utilisés pour les glaçures de céramiques.

21. Quelques dépôts ont été notés au Prah Khan, dans les superstructures de la tour centrale et de la tour sud du Gopura IV Ouest, où plusieurs blocs présentaient sur leur arase supérieure des « petites cavités tapissées de feuilles de plomb et contenant des fragments de quartz et de granit » (juin, juillet 1944 et février 1945). Récemment, un alignement de six tortues en plomb a été dégagé lors des travaux d'anastylose de la face orientale du perron nord de la terrasse des Eléphants, parmi un réseau dense de dépôts de fondation (cf. infra, p. 402-407, tableau p. 400). 
portugais, mentionne à propos du Cambodge, le plomb et l'étain parmi les «produits susceptibles d'y être négociés, sans que l'on puisse faire le départ entre ce qui était importé ou, au contraire, exporté »(Groslier, 1958, p. 144). Au siècle suivant, Christoval de Jaque, un autre voyageur portugais, cite le plomb, l'étain et l'argent parmi les productions du pays (Groslier, 1958, p. 152-153). Même si l'on peut douter comme B.-P. Groslier de l'exactitude de ce témoignage qui indique une exploitation active des galènes argentifères du pays (cf. infra, p. 197), il n'en demeure pas moins qu'il suggère au moins une métallurgie du plomb. Enfin, au XIX ${ }^{\mathrm{e}}$ siècle, le plomb était utilisé dans le revêtement de grands piédestaux ou des frontons, sous forme de lames de «plomb vitrifié blanc, vert vif ou rubis » (Groslier, 1930, p. 50). Il servait aussi, avec l'étain, à la confection de bijoux dans certaines tribus du Cambodge (Malleret, 1960, p. 270).

Les données recueillies montrent donc l'existence d'une métallurgie du plomb dès le début de la période historique qui se poursuit durant la période angkorienne. D'importance modeste par la quantité de ses productions qui semble nettement plus concerner le domaine de la construction liée au pouvoir religieux et royal que celui de la vie civile, elle peut avoir répondu à un aspect utilitaire et être restée à Angkor rudimentaire et annexe, vraisemblablement associée à d'autres ateliers - ferronniers, bronziers ou argentiers ? Mêlant suivant la disponibilité et la commande les métaux dont le plomb qui peut entrer dans la composition du samrit, «l'alliage le plus noble » - des ateliers similaires existaient encore au début du siècle à Siemreap (Giteau, 1975, p. 3 et 27). Cette pratique se perpétue en quelque sorte aujourd'hui avec le seul atelier de la ville, qui produit essentiellement les «bronzes pour touristes » à la cire perdue avec du cuivre récupéré de bols ou de câbles électriques, mais ne dédaigne pas, à l'occasion, et si on lui fournit le métal, à couler du plomb afin d'alourdir certains socles de statuettes destinées aux fondations des pagodes modernes.

\section{Provenance du métal?}

La quantité de plomb nécessaire pour réaliser la couverture d'un pavillon, aussi modeste soit-il, implique une quantité conséquente qui ne peut que soulever la question de la provenance du métal. Plusieurs solutions se présentent, sans d'ailleurs être incompatibles : réemploi, exploitation de filons locaux, ou importation.

\section{Réemploi}

Le procédé du réemploi fut souvent pratiqué dans la civilisation angkorienne : les palimpsestes architecturaux que constituent certains temples en sont les exemples les plus frappants. Il semble en avoir été de même pour les métaux et les alliages, rendant du même coup difficilement utilisable les analyses chimiques de ces objets (Malleret in Bezacier, 1972, p. 284-285). Dans son étude sur l'art du bronze dans l'ancien Cambodge, J. Boisselier souligne la fréquence de la fonte des idoles à partir des butins enlevés dans les sanctuaires des territoires conquis. Suggérant que cette réutilisation était une règle, il résume schématiquement en constatant que "la péninsule indochinoise indianisée semble n'avoir œuvré, presque jusqu'à la période contemporaine, que sur des quantités de bronze et de métaux précieux à peu près constantes mais dont la répartition entre les divers royaumes variait en fonction des déplacements d'hégémonie » (1967, p. 278-280).

Bien que l'auteur fournisse une vision particulièrement intéressante de « l'importation » des métaux en soulignant l'importance des conquêtes, le rôle majeur de la réutilisation semble devoir être relativisé, au moins pour expliquer la survivance des fameux bronzes khmers de Mandalay. Dans le cas particulier du plomb, le recyclage 
dû certes être possible d'autant que ce métal se prête aisément à la fonte. Mais le rapt d'une statue en or ou en argent, chargée d'un aspect religieux qui semble faire défaut aux objets de plomb, paraît plus aisé et justifié que la récupération des scellements de crapaudines ou des crampons. Certes, peu de scellements nous sont parvenus intacts, et certains temples - Bakong pour ne citer qu'un exemple - ont subi un arrachement systématique de leurs crampons. Mais, ne pouvant dater ces agissements, dont il n'est d'ailleurs pas certain qu'ils eussent été partout systématiques, y voir le fait d'une quelconque conquête serait par trop hypothétique. D'autre part, l'utilisation du plomb dans les scellements à l'époque angkorienne, dont le nombre et l'importance semblent varier au fil de l'évolution constructive des temples, apparaît comme un choix technique délibéré qui ne s'embarrasse qu'accessoirement d'une disponibilité aléatoire provenant de butins ou de réemploi. Par ailleurs, il eût été difficile, vu les quantités importantes nécessaires à la réalisation d'une couverture de plomb (cf. infra, p. 200), que l'intégralité du métal ait été obtenue de butins. Que le plomb provienne en partie du recyclage des tuiles du palais du souverain précédent semble probable, particulièrement pour les éléments dégagés à la terrasse des Éléphants comme nous l'avons déjà évoqué plus haut. Mais ceci ne fait que repousser la date de l'approvisionnement originel sans pour autant résoudre le problème de sa provenance ${ }^{22}$. Enfin, et d'une manière plus générale, la conception d'une toiture en plomb apparaît tellement particulière et liée à la personne du souverain que celui-ci pouvait se permettre pour se loger sous du plomb, de n'être soumis ni aux aléas de ses campagnes militaires, ni aux contingences irrégulières du réemploi. Il devait donc aussi bénéficier soit de la production d'un site de galène, soit de l'ouverture sur un réseau commercial où le plomb était disponible.

\section{Exploitations locales}

Nous constatons que peu d'éléments plaident pour un approvisionnement suffisant strictement local. Certes, quelques filons quartzeux - Bo Su Trup et Phnom Kambor, à 90 et 70 kilomètres au nord-ouest de Siemreap dans les environs de Samrong présentent quelques minéralisations en galène, mais aussi en or, argent, chalcopyrite et blende. En plus de divers essais d'exploitation aurifère au début du siècle, « des traces d'anciennes exploitations artisanales " malheureusement non datées y ont été remarquées (Dottin, 1971, p. 33). Mais ces filons sont assez pauvres et leur intérêt principal semble avoir résidé dans l'exploitation de l'or. La région proche d'Angkor ne semble posséder par ailleurs d'autre site de galènes ni gîte stannifère. L'imprécision du caractère «d'ancienneté » des traces d'exploitation des sites repérés par le BRGM nous cantonnerait au domaine du doute si nous ne pouvions aussi noter dans l'épigraphie un cas intéressant d'exploitation minière. L'inscription K. 180 du Prasat Pram (LL251) est à ce sujet remarquablement explicite et décrit une terre "pourvue d'éléphants, de buffles, d'esclaves mâles et femelles, de taureaux apprivoisés, riche en trésors, en argent, en pierres précieuses, en métaux, contenant des terrains cultivés » (st. XXVII Coedès, 1989 , p. $33-42)^{23}$. Si de l'argent était extrait au Cambodge, il ne pouvait l'être

22. En comptant certaines pertes liées au procédé du réemploi, un minimum d'approvisionnement en métal neuf reste indispensable, à moins d'envisager que les toitures couvertes de plomb aient été de plus en plus réduites, au fur et à mesure des réemplois, telles des poupées russes. Par ailleurs, pour peu que le palais du souverain précédent ait succombé à un incendie, et donc qu'une partie importante ne puisse être réutilisée, cet approvisionnement en plomb neuf se révélerait particulièrement inévitable. Nous n'avons cependant pas retrouvé de saumons de plomb dans les sondages.

23. L'inscription sanskrite relate la fondation au $X^{\mathrm{e}}$ siècle d'un sanctuaire et l'organisation des terres avoisinantes. La mention d'une terre «riche en trésors, etc. » est d'autant plus claire que, quelques stances plus bas, l'inscription précise qu'une seconde terre voisine possède aussi « terre, mines, champs, serviteurs, villages, etc. » (st. XLV). 
que de galènes argentifères, nul site de minerai d'argent natif n'étant connu (Malleret, 1962 , p. 461) ${ }^{24}$. Bien que le plomb ne soit pas spécialement indiqué, il est clair que cette inscription atteste de son exploitation à l'époque angkorienne, dans la région du Prasat Pram. Celui-ci est situé à environ 70 kilomètres au nord-est d'Angkor, à michemin entre Beng Méaléa et Koh Ker. Bien qu'aucun gisement n'ait été relevé dans cette zone - dont on peut douter d'ailleurs qu'elle ait jamais été l'objet de prospections minières approfondies - les indications de l'inscription apportent un certain intérêt à des informations que nous avions recueillis à l'occasion d'une recherche indépendante de la présente étude et antérieure à celle-ci. Ces informations faisaient état de très nombreux objets de plomb trouvés lors d'un pillage systématique qui a ravagé en 1982 les sites au nord-est du Phnom Kulen ${ }^{25}$, et de la présence éventuelle d'un filon de plomb près du Phnom Méas, au nord-est du village Ta Siem... situé à quelques kilomètres du Prasat Pram ${ }^{26}$.

Nous devons cependant élargir la notion d'approvisionnement local au Cambodge actuel, voire même à l'empire angkorien. En 1958, B.-P. Groslier rejetait le témoignage de C. de Jaque - qui, rappelons-le, indique le plomb, l'étain et l'argent parmi les productions du Cambodge du XVII e siècle - , en faisant remarquer que les filons correspondants «n'ont pas été repérés et il est douteux qu'ils aient jamais été exploités ». Diverses études ont depuis révélé des sites de minéralisation en galène, en particulier dans certains phnom de la province de Kompong Speu où une mission du BRGM a relevé des indices d'argent avec «des traces d'exploitations anciennes » (Dottin, 1971, p. 30 et 47-50). De même, pour l'étain, une étude du même institut montre des gisements de cassitérite dans la même province. Bien que ces sites soient d'importance très modeste et que ces traces d'exploitations anciennes restent bien imprécises, les objections de B.-P. Groslier sont à relativiser en l'attente d'études approfondies sur ces sites. Il reste que ces ressources semblent dans l'état actuel assez maigres, et il est possible que des régions parfois plus éloignées de la capitale angkorienne aient pu être appelées à contribution. Nous devrons donc élargir une fois de plus la notion d'approvisionnement local, à l'échelle de l'empire cette fois, pour envisager les ressources minières de diverses régions environnantes qui ont en commun de présenter des vestiges khmers qui montrent un certain rattachement à Angkor. Parmi celles-ci, quelques gisements dans le Bas-Laos, dans les environs de Bassac et d'Attopeu, sont assez productifs en galènes argentifères (Malleret, 1962, p. 8 et 129). De même, pour l'étain et le cuivre, des gisements de cassitérite et de chalcopyrite sont connus au Moyen-Laos ${ }^{27}$. En Thaïlande, des sites ont été repérés pour l'étain sur le

24. Faute d'analyses d'objet en argent pour quantifier un éventuel pourcentage de plomb, il est impossible d'évoquer une galène pour la provenance de l'argent utilisé. Les résultats obtenus pour Océo ne sont d'ailleurs guère révélateurs et permettent de douter des conclusions d'une telle approche si les pourcentages de plomb sont faibles (cf. p. 192, note 15).

25. Ces objets, dont des tortues ou des saumons, auraient été revendus « par centaines » au poids à Sutnikom et fondus pour fournir... des percuteurs d'obus. Nous remercions $F$. Luco pour nous avoir signalé ce déplorable événement et rapporté le récit d'un témoin. Nous avons de notre côté recoupé cette information auprès d'un second témoin qui, originaire de cette région, l'a parcourue avant-guerre avec Tep Mey, informateur de J. Boulbet.

26. Nous n'avons pu malheureusement vérifier ces renseignements, la zone restant encore inaccessible. Notre informateur a aussi mentionné l'existence au sommet du Phnom Méas (la montagne d'or) d'une colonne de $60 \mathrm{~m}$ de haut, sur un soubassement carré de $4 \mathrm{~m}$ de côté, l'ensemble en plomb massif. La colonne aurait été détruite par les Issaraks pour fournir des plombs de cartouche mais une partie importante du soubassement aurait subsisté jusqu'en 1961. En retranchant une bonne dose d'exagération, il reste que l'histoire d'un objet aussi singulier fait étrangement écho aux centaines de kilos de plomb pillés dans les temples de la région... et à l'inscription du Prasat Pram voisin.

27. B. P. Groslier envisageait d'ailleurs que le cuivre et l'étain khmer provenaient des gisements du Moyen-Laos (J. Dumarçay, communication personnelle). 
plateau de Korat (Malleret, 1960, p. 266, n. 1 et p. 267, n. 1) et pour le plomb dans les districts de Si Sawat et de Sangkhla Buri (province de Kanchanaburi). Bien que des datations au carbone 14 de creusets recueillis dans ces deux derniers sites peu éloignés du Prasat Muang Sing ont montré l'existence d'une exploitation ancienne remontant au mieux au début du XIVe siècle, il demeure probable que le plomb ait été extrait en Thaïlande antérieurement à cette période (Howitz, 1977, p. 300-301). Il apparaît alors que ces ressources minières ont pu être sollicitées dans diverses parties de l'empire khmer. Un approvisionnement local — avec un sens élargi à l'empire et à ses franges semble donc être envisageable.

\section{Importation}

Mais divers éléments suggèrent aussi une provenance plus lointaine. Une importation était déjà probable durant la période du Fou-nan, pour laquelle Malleret estime qu'il «n'est pas impossible que l'argent [et avec lui, le plomb] ait pu venir du Nord, et se trouver introduit par la voie maritime, dans le Delta du Mékong » (1962, p. 8). Bien qu'Angkor soit géographiquement en retrait des voies maritimes et qu'il soit difficile de voir la capitale khmère comme une grande cité portuaire, l'ouverture sur le Tonlé Sap et, à travers celui-ci, sur la voie du Mékong, se connectait au vaste réseau relié au golfe de Siam et à la Chine - en fait à la Méditerranée asiatique. Une réelle potentialité d'importation existait donc depuis des origines diverses, tant à l'intérieur qu'à l'extérieur de l'empire. Les sources épigraphiques et de nombreuses céramiques chinoises attestent par ailleurs de ces mouvements de biens. Mais, pour le plomb - et l'argent, dont la production doit être étroitement associée à celle du plomb - nul objet d'origine chinoise n'a été retrouvé comme à Oc-éo (Malleret, 1960, p. 372). Zhou Daguan inclut certes l'argent dans les «marchandises chinoises qu'on désire » et il mentionne ce métal dans les transactions importantes (Pelliot, 1951, p. 27) ${ }^{28}$. On ne saurait conclure de ce récit que l'ensemble de l'argent était importé, encore moins qu'il n'était importé que de Chine, et il serait de même exagéré d'en déduire directement une importation du plomb. Celle-ci ne semble néanmoins pas irréaliste si l'on considère les trois paramètres connexes suivants : l'emploi particulier du plomb à la période angkorienne, l'importation de l'argent qui prévalait à la période post-angkorienne, et la possible implication de la communauté chinoise dans la métallurgie à Angkor.

Nous avons remarqué qu'à Angkor, les éléments de plomb avaient été plutôt recueillis dans un contexte monumental, associés soit au palais royal pour nos éléments de couverture, soit aux temples pour les scellements. Rares sont les objets à caractère « civil », à la différence des nombreux témoins retrouvés à Oc-éo et des objets « de caractère volontiers populaire » en bronze à Angkor (Boisselier, 1967, p. 277). Bien que l'argument ad silentio n'est pas entièrement probant puisque l'on doit encore rappeler que les recherches réalisées à Angkor ont principalement concerné les sites monumentaux, cette absence d'objets civils en plomb suggère que ce matériau était peu courant, réservé à des usages où le problème de l'approvisionnement était secondaire. Quant aux lingots de plomb qui ont été retrouvés dans la nécropole de Sra Srang, il n'est pas exclut que ces objets avaient été détournés de leur fonction primitive pour être

28. L'auteur chinois « déclare que le Cambodge angkorien ne produit ni or ni argent, mais il le dit sous une forme hésitante en ajoutant que l'or et l'argent sont particulièrement estimés » (Malleret, 1962, p. 6, note 1). Quelques sites aurifères sont connus au Cambodge et nous avons vu plus haut que l'exploitation argentifère y existait. Aussi l'hésitation de Zhou Daguan nous semble indiquer plutôt une production locale modeste, insuffisante pour couvrir la demande angkorienne et justifiant la mention de l'argent chinois dans les marchandises à importer. 
réutilisés dans un rituel de sépulture qui explique leur présence à cet endroit ${ }^{29}$. Une fois dépouillés de ce contexte particulier, les saumons ou les troncs de pyramide ne représentent-ils pas de simples lingots de plomb utilisés lors du commerce de ce métal ou comme ballast pour les vaisseaux de commerce ${ }^{30}$ ?

Autant que nous puissions tirer quelques enseignements de la situation qui prévalait durant la période post-angkorienne, il est intéressant de souligner pour celle-ci l'importance de l'importation de l'argent, et implicitement la faiblesse de la production locale que nous avons noté plus haut. Comment expliquer autrement que, jusqu'à la période contemporaine, le «développement croissant de l'orfèvrerie de l'argent doit être noté comme l'une des caractéristiques essentielles de la période post-angkorienne » (Boisselier, 1966, p. 355) ${ }^{31}$, alors que les galènes argentifères du pays ne semblent jamais avoir été exploitées à grande échelle (Dottin, 1971, p. 30) ${ }^{32}$ ? Cette situation se retrouve d'ailleurs durant la période contemporaine où, avant la période dramatique des années soixante-dix, l'artisanat khmer de l'argent ciselé était particulièrement réputé, alors qu'il n'utilisait presque exclusivement que du métal d'importation. Il est alors tentant de suggérer une certaine continuité et que cette faiblesse de la production locale ait déjà existé à l'époque angkorienne.

Enfin, il est possible que la communauté chinoise à Angkor ait joué un certain rôle dans la métallurgie bien qu'il demeure hypothétique d'en dégager précisément ses aspects. La présence de chinois est confirmée par Tcheou Ta-kouan, et son souvenir semble s'être gardé à travers certains toponymes dans la région d'Angkor. Mais les sources sont avares en détails sur leurs activités et aucune ne permet de penser qu'ils aient pu prendre part directement à l'exploitation minière. Leur implication dans le commerce de biens est par contre attestée depuis les premiers siècles de notre ère et B. P. Groslier estime qu'au XVe siècle, les importations étaient « entièrement dans les mains des chinois » (1958, p. 162). Sans imaginer une telle hégémonie à la période angkorienne, il est certain que les chinois avait déjà une importante activité de ce type, quitte à prendre femme sur place pour « profiter en outre des aptitudes commerciales de celle-ci » (Pelliot, 1951, p. 27 et 34). Comme ailleurs en Asie du Sud-Est (Lombard, 1990, t. II, p. 228-229), la communauté chinoise y exportait des produits métalliques manufacturés en Chine. "Les étains de Tchen-tcheou» en sont un exemple et pourraient correspondre aux «ustensiles et verseuses en alliage blanc » mentionnés dans le même récit de Zhou Daguan (Pelliot, 1951, p. 27. Yang, 1994, p. 231) ${ }^{33}$. Il semble même que les chinois ont pu parfois prendre une part active dans la métallurgie angkorienne: les Chroniques Royales révèlent indirectement la présence d'une communauté de forgerons chinois qui, en 1434, suit les pérégrinations de la capitale royale lors de l'abandon d'Angkor ${ }^{34}$. Enfin, nous avons évoqué plus haut l'éventualité

29. J. Dumarçay a eu l'amabilité de nous suggérer que ces lingots peuvent montrer une pratique de la fraude, ou du moins du faux-semblant, « où une simple feuille d'or ou une quelconque peinture jaune enveloppe une âme d'étain ou de plomb » (Malleret, 1962, p. 8).

30. Des lingots en plomb de formes diverses, dont certains proches d'un tronc de pyramide, ont été retrouvés dans diverses épaves plus tardives étudiées dans le golf de Thaïlande. Ces lingots ont pu souvent servir de ballast. L'une d'elles cependant, datée du début du XVII ${ }^{\mathrm{e}}$ siècle, présente un nombre de lingots qui indique que ce métal en était la principale cargaison (Howitz, 1977, p. 302).

31. Notons par ailleurs l'apparition de monnaies d'argent au XVe siècle (Malleret, 1962, p. 134). Exemples de monnaies en argent du XVII e siècle in Lombard, 1967, p. 290 et planche IX.

32. «Depuis les mines d'argent "activement exploitées" dont parle C. de Jaque au XVII' siècle, en admettant encore que le renseignement soit exact, l'argent ne semble pas avoir été exploité à grande échelle au Cambodge » (Dottin, 1971, p. 30).

33. Des « objets chinois » servaient par ailleurs pour les petites transactions (Pelliot, 1951, p. 27).

34. Parmi les grands travaux que le roi Ponâ Yàt lance lors de son établissement à Phnom Penh, les Chroniques mentionnent le creusement d'un rempart/fossé périmétral dont sa partie septentrionale accueille, sur ordre royal, «des chinois pour forger des armes » (Cœdès, 1989b, p. 25). Cette 
de voir des artisans chinois comme dénominateur commun dans les couvertures en plomb ou en étain que nous retrouvons dans les palais d'Angkor, d'Ayuthia ou même d'Aceh.

Ces divers points, même s'ils ne comblent pas l'absence de sources explicites, permettent cependant de suggérer que le plomb ait pu être importé afin de combler les insuffisances d'une production locale face à la commande exceptionnelle que constitue la réalisation d'une couverture métallique.

\section{Des répercussions structurelles?}

Afin d'évaluer la quantité de métal nécessaire à la réalisation d'une couverture en plomb, nous devons rechercher son poids propre qui pourrait sembler, à première vue, plus important que celle d'une toiture «classique " d'éléments en terre cuite. Nous avons donc tenté de dégager, même approximativement, le poids d'une couverture de ce type pour pouvoir envisager d'éventuelles répercussions sensibles dans les charpentes ${ }^{35}$. Les résultats montrent que les couvertures de plomb non seulement n'entraînent aucune surcharge, mais qu'elles peuvent même permettre un gain de poids. Deux configurations doivent être distinguées : la couverture avec tuiles canal et couvrejoints, et celle avec tuiles plates.

Dans le premier cas, une solution « légère » utilise pour $1 \mathrm{~m}^{2}: 16,3$ tuiles canal larges avec pureau à $5 / 7(2000 \mathrm{~g})$ et 23,4 tuiles couvre-joints longues avec pureau à $1 / 2$ $(1900 \mathrm{~g})$. Elle représente une charge d'environ $80 \mathrm{~kg} / \mathrm{m}^{2}$. Une variante «lourde » serait composé de 31,5 tuiles canal étroites $(1670 \mathrm{~g})$ et 39,1 tuiles couvre-joints courtes $(1700 \mathrm{~g})$ avec des pureaux de $1 / 2$. Elle correspondrait à un poids de $120 \mathrm{~kg} / \mathrm{m}^{2}$. Si l'on compare ces chiffres ${ }^{36}$ à ceux fournis par l'étude de J. Dumarçay (1973, p. 10-11) pour les couvertures de terre cuite — de 65 à $110 \mathrm{~kg} / \mathrm{m}^{2}$ - nous constatons que la couverture métallique n'implique pas de surcharge notable. Une différence aussi modeste n'a pas dû entraîner d'importantes modifications des structures, elles-mêmes très lourdes.

Quant à la couverture en tuiles plates, nous avons estimé le pureau, en fonction d'un recouvrement latéral, à environ 1/2 $(0,54)$. Quarante-quatre tuiles ${ }^{37}$ seraient nécessaires pour couvrir $1 \mathrm{~m}^{2}$. Cette estimation donne une charge inférieure à $50 \mathrm{~kg} / \mathrm{m}^{2}$. Ce résultat permettrait de qualifier de «léger» ce type de toiture, en tout cas, plus léger que n'importe quel type de couverture en terre cuite connu.

\section{Les couvertures en plomb dans les architectures figurées}

La mise au jour d'éléments métalliques plats permet tout d'abord de confirmer une suggestion émise en 1973 par J. Dumarçay. L'auteur de Charpentes et tuiles khmères suggérait de voir dans certaines représentations d'édifices à pureaux en losange ou en

communauté de forgerons semble donc avoir déjà existé à Angkor pour jouir d'une telle reconnaissance.

35. L'estimation du poids de la couverture prend en compte deux paramètres difficiles à restitucr : le poids de l'élément et son profil d'origine. Pour le premier, nous nous sommes fondés sur le poids le plus fort constaté pour les éléments du même type - ce qui nous permet de minimiser la variation de poids due à celle de l'épaisseur. Le second découle d'hypothèses élaborées par comparaison avec des éléments du même type en terre cuite.

36. Les chiffres ne comprennent pas le poids du lattis.

37. Pour ce calcul, nous nous sommes fondés sur le poids du seul exemplaire complet dégagé. 
carré des toitures soit en bardeaux, soit en feuilles de plomb $(1973$, p. 26$){ }^{38}$. Il est clair que la seconde hypothèse est dorénavant nettement plus probable et que ces reliefs font référence à une couverture de tuiles plates métalliques.

Il n'est d'ailleurs pas impossible que, les propriétés du matériau aidant, une couverture en feuilles de différents modules ait pu être déclinée sur des formes courbes, même relativement complexes. Le métal pouvait être tordu, soudé, coupé, martelé, les éléments adaptés in situ à des configurations particulières. Les handicaps majeurs des éléments de couverture en terre cuite disparaissaient avec ce matériau : fragilité de la pâte impliquant une difficulté pour la taille après cuisson, nécessité d'éléments modulaires «préfabriqués » entraînant une couverture à l'ordre prédéterminé et rigide, utilisation de grandes quantités de mortier pour corriger les problèmes d'étanchéité posés par les ressauts des tuiles inadaptées à des toitures courbes... Par ailleurs, une couverture de feuilles métalliques permettrait de réaliser des structures plus fines, voire même temporaires puisque le matériau est facile à mettre en œuvre rapidement et aisément recyclable. Notons en effet que divers pavillons, souvent qualifiés de temporaires, sont représentés sur les bas-reliefs du Bayon et montrent des couvertures courbes et élancées avec des éléments au pureau losange ou carré. Images d'architectures éphémères couvertes de toiles, il est aussi envisageable d'y voir les représentations de couverture en métal ${ }^{39}$. Citons pour exemple, le radeau duquel le Roi assiste à la bataille navale qui oppose sa flotte à celle des Chams (Dumarçay, 1973, fig. 67), ou, légèrement plus loin à l'ouest, au registre supérieur, un pavillon construit sur un ponton sous lequel le personnage central, masqué par une fenêtre à balustre et une tenture, est encadré de servantes (pl. 6). Ce relief, dont la moitié droite manque, montre un édifice composé d'un corps central avec couverture à quatre noues, encadré par trois avant-corps successifs décroissants. Les toitures, courbes, portent toutes des éléments au pureau losange.

Quelques rares exemples de représentations d'édifices, tous situés dans l'aile orientale de la galerie sud de la troisième enceinte d'Angkor Vat, présentent un type de couverture à pureau losange associé à une couverture classique de tuiles canal et couvre-joints. L'analyse des détails de couverture des nombreux bâtiments représentés sur le registre supérieur de cette célèbre galerie des Cieux et des Enfers, montre une certaine fantaisie de la part des sculpteurs, voire même parfois une remarquable incompréhension des systèmes de couverture ${ }^{40}$. Il reste que, faute de mieux, et en relativisant les indications de détail, trois pavillons ont retenu notre attention. Deux surplombent «le tas de charbons ardents » (cliché 591) et «le lac de moelle » (cliché 590), et présentent un dôme recouvert d'éléments au pureau, respectivement, en losange

38. Notons que des couvertures de chaume maintenu par un treillis apparent croisé et oblique, comme il en existe encore en Thaïlande dans certains édifices contemporains « traditionnels », pourraient aussi avoir été représentées de la même manière.

39. Différentes plaques de revêtement en bronze ont été trouvées à Angkor. Bien que la plupart étaient assurément des placages destinés aux portes, aux murs ou aux piédestaux (Boisselier, 1966. p. 347), il n'est pas impossible que certaines puissent provenir de couvertures. Notons d'ailleurs que la couverture de plaques métalliques est indiquée dans le Mayamata (Dagens, 1970, p. 12 et 374 ).

40. Prenant « quelques libertés avec la réalité » (Dumarçay, 1973, p. 20), les sculpteurs ont aussi traduit dans la pierre leur interprétation - voire parfois leur propre incompréhension - des systèmes de couverture : alors que certains se sont attachés à montrer le relief des tuiles couvre-joints, d'autres ont concentré leur attention sur l'alignement des épis de faîtage avec les rangés de tuiles couvre-joints et d'about, d'autres encore n'en eurent cure. D'autres exemples de ce type de variation montrent à l'évidence que plusieurs équipes étaient au travail en même temps, et suggère même que certaines ont réalisé au moins deux tronçons de panneau (voir par exemple la similitude troublante dans le traitement original des couvertures sur les clichés 588 et 599). Le numéro des clichés fait référence au recueil : Le temple d'Angkor Vat, troisième partie, la galerie des bas-reliefs, t. III, Paris, 1932, Mémoires archéologiques de l'EFEO II. 
et en carré, encadré par des avant-corps couverts avec un système classique. Ces deux bâtiments encadrent un troisième, situé au-dessus de « l'enfer des damnés au ventre de fer rougi » (cliché 590) qui se compose de trois toits superposés : les deux supérieurs présentent des pureaux losanges, le dernier - les avant-corps - un système classique. Si, comme nous le pensons, les éléments en losange sont l'indice d'une couverture métallique $^{41}$, il est probable, à moins d'envisager des structures à couvertures mixtes métal / terre cuite, que les niveaux inférieurs des toitures de ces trois pavillons représentent des tuiles canal, couvre-joints et d'about réalisées en plomb.

L'existence de tuiles « classiques » en métal, similaires à celles de terre cuite, plaide non seulement en ce sens, mais montre aussi que beaucoup d'autres reliefs pourraient en représenter. Nous avons vu plus haut que ce type de couverture n'entraînait pas de modification structurelle. Par ailleurs, outre la similitude observée pour les tuiles canal et couvre-joints, les motifs présentés sur les antéfixes reprennent des ornements déjà rencontrés sur les tuiles d'about. Il semble dès lors vain de repérer une couverture métallique " classique » dans ces nombreuses représentations en bas-relief. Il nous suffira ici de relativiser les interprétations d'architectures figurées sur les bas-reliefs, en gardant en mémoire la parfaite similitude entre les deux types de couvertures.

\section{Les appartements royaux?}

Un bas-relief a retenu plus spécialement notre attention : celui dit du «palais royal ". Situé sur le panneau médian de l'aile orientale de la galerie sud du premier étage du Bayon, cette représentation montre un ensemble complexe de constructions, toutes recouvertes d'éléments à pureaux en losange (Dumarçay, 1973, fig. 68). La découverte de tuiles plates métalliques n'apporte cependant pas de nouveaux éléments pour reprendre les tentatives de restitution du palais royal de G. Groslier. Nous ne relèverons ici qu'une association tentante entre ce relief, les éléments de couverture en plomb dégagés au perron nord de la terrasse des Éléphants, et la mention de « l'appartement principal » du palais royal par Zhou Daguan. Ce récit n'est d'ailleurs guère explicite, et mérite que l'on s'y attache un instant. Le passage indiquant les tuiles en plomb se situe dans les premières lignes du chapitre relatif aux habitations $(\S 2)$, dont nous citons la traduction de P. Pelliot (1951, p. 12):

«Le palais royal ainsi que les bâtiments officiels et les demeures des nobles font tous face à l'Est. Le palais royal est au Nord de la Tour d'Or et du Pont d'Or; proche de la porte (?), il a environ cinq ou six stades de tour. Les tuiles de l'appartement principal sont en plomb; sur les autres bâtiments du palais, ce sont toutes des tuiles d'argile, et jaunes. Linteaux et colonnes sont énormes; sur tous, des Buddha sont sculptés et peints. Les toits (?) sont imposants. Les longues vérandas, les corridors couverts s'élancent et s'enchevêtrent, non sans quelque harmonie. Là où le souverain règle ses affaires, il y a une fenêtre en or; à droite et à gauche du châssis, sur des piliers carrés, sont des miroirs; il y en a environ quarante à cinquante, disposés sur les côtés de la fenêtre. Le bas de la fenêtre est en forme d'éléphants. »

« J'ai entendu dire qu'à l'intérieur du palais, il y avait beaucoup d'endroits merveilleux; mais les défenses sont très sévères, et il m'a été impossible de les voir ».

41. On notera toutefois la similitude des motifs que présentent les couvertures à pureau losange avec ceux indiqués sur les vélums et les tentures, ce qui pourrait suggérer une couverture de tissus. Mais la présence de tuiles sur les avant-corps serait surprenante. 
Suit alors un second paragraphe relatif à ces « endroits merveilleux » et à la légende rapportée par «tous les indigènes » sur les ébats nocturnes du souverain au sommet de la «tour d'or » - le Phimeanakas.

Les détails du récit de l'auteur chinois doivent naturellement être pris avec réserve car P. Pelliot a rencontré plusieurs difficultés pour la traduction de certaines phrases. Mais le premier paragraphe, essentiellement descriptif, apparaît comme observé et nous lui accorderons donc une certaine crédibilité. Cependant, la localisation exacte des édifices décrits - dont l'appartement principal - reste sujette à caution tant les repères nous manquent et les indications du récit sont en apparence contradictoires. Envisageant la présence de pavillons et de galeries édifiés sur les terrasses royales, de nombreux auteurs ont localisé la salle d'audience au perron central ${ }^{42}$ et ont proposé de voir dans ce passage du texte de Zhou Daguan une image de la façade orientale des terrasses royales plutôt que celle d'édifices situés à l'intérieur du palais. L'appartement principal correspondrait en ce cas à une salle accolée à celle des audiences, et serait à situer vraisemblablement dans l'axe du palais, au centre du perron central. Ceci semble être par ailleurs confirmé dans un paragraphe suivant (Pelliot, 1951, p. 16, §6) par l'appellation d'appartement principal attribuée à la pièce d'où le souverain domine la salle d'audience par une fenêtre en or. Doit-on alors envisager que cette pièce correspond à celle mentionnée sous une couverture de plomb?

Cette interprétation spatiale achoppe néanmoins sur quelques points gênants. Le premier, bien que peu significatif, repose sur le fait que les divers dégagements et sondages qui ont été réalisés sur les terrasses et en particulier au perron central ${ }^{43}, n$ 'ont jamais permis la moindre découverte d'éléments de couverture en plomb. Un second point réside dans les incertitudes notées par P. Pelliot à propos du sens de l'expression traduite par appartement principal (mot à mot « appartement correct » mais rendue dans la première traduction de 1902 et dans une note de 1951 par "appartement privé », Pelliot, 1951, p. 146 et 149). Cette expression, que Zhou Daguan utilise ailleurs tant pour signaler des pavillons particuliers dans les demeures des nobles que pour qualifier la première épouse du souverain, ne semble pas devoir être prise dans un sens restrictif impliquant l'unicité ; il semble même avoir été appliqué pour distinguer dans un groupe de bâtiments un édifice plus ou moins central ou d'apparat. Que l'appartement principal couvert de plomb soit le même que celui de la salle d'audience reste donc probable bien que non assuré. Enfin, le point qui nous semble le plus net découle d'une apparente contradiction dans le récit de Zhou Daguan : l'auteur indique ne pas avoir eu accès « aux endroits merveilleux » à l'intérieur du palais $(\$ 2)$, alors qu'il précise plus loin avoir pénétré au palais pour assister aux audiences (\$6). P. Pelliot note que la première indication confirme que Zhou Daguan "n'a eu accès que dans les constructions extérieures du palais, jusqu'à la salle d'audience. Par la "fenêtre d'or », le roi communiquait avec ceux à qui il donnait audience sans avoir à sortir du palais, et par suite les étrangers n'avaient jamais à pénétrer dans les bâtiments du palais proprement dit» (1951, p. 154). Où doit-on donc localiser ces lieux appelés, constructions extérieures du palais ou bâtiments du palais proprement dit, dont le point de contact se situerait justement à l'endroit de cette fenêtre d'or ? Ceci peut difficilement s'expliquer par un amalgame fait par Zhou Daguan entre le palais intra

42. «Dès les premiers travaux sur Angkor on reconnut que la "terrasse" des éléphants était, en réalité, le soubassement de la salle d'audience déployée devant le Palais Royal d'Angkor Thom » (Groslier, 1969, p. 19).

43. En 1927, le perron central a été l'objet de recherches assidues par H. Marchal qui y cherchait un élément crucial pour contredire la thèse de P. Stern sur la datation du Bayon. Mais en octobre 1927, H. Marchal note dans son rapport: «Stern et ses partisans triomphent et je suis obligé de les féliciter de leur sagacité ». 
muros et les pavillons en avant de celui-ci, sur les terrasses royales, nettement séparés par une large douve et une importante dénivellation. Il semble plutôt que cette contradiction repose sur l'appellation de «palais » qui recouvre plusieurs espaces en partie distincts. Il est alors intéressant de rappeler que l'enceinte du palais royal est scindée par des murs de latérite en quatre ou cinq tronçons ${ }^{44}$, qui délimitent ainsi une succession de « cours », d'est en ouest. Il est certain que Zhou Daguan n'a pu accéder à la seconde cour, où se situe la «tour d'or ». Mais sa description permet d'envisager qu'il a pénétré dans la première, «dans » l'enceinte du palais. C'est dans cette première cour que se situerait alors la salle d'audience, communiquant par la «fenêtre d'or » avec la seconde cour et «les bâtiments du palais proprement dit ». De même que la « fenêtre d'or » observée par Zhou Daguan présente certaines analogies avec celles qui étaient en usage au Siam ou en Birmanie, la localisation de la salle d'audience à l'intérieur de l'enceinte du palais n'est pas sans rappeler les configurations que présentent les palais d'Ayuthia ou de Mandalay, où les audiences se passaient toujours dans le palais ${ }^{45}$.

L'accès à cette première cour du palais est par ailleurs suggéré par le caractère très particulier des huit inscriptions que portent les piédroits des quatre baies de l'avantcorps ouest du gopura oriental de l'enceinte du palais (K. 292). Ces inscriptions sont certes largement antérieures au passage de Zhou Daguan puisque le serment des fonctionnaires qui y est gravé a été prononcé en 1011. Mais la présence en ce lieu de la formule du serment et des noms de ceux qui ont ainsi juré fidélité, ne peut être innocente. Elle semble plutôt correspondre à la volonté de Suryavarman Ier de rappeler aux intéressés leur serment, impliquant donc l'accès de ceux-ci à la première cour du palais.

$\mathrm{Si}$, comme nous le pensons, la salle d'audience était bien située dans la première cour, la description des couvertures en plomb concernerait donc un pavillon situé dans l'enceinte du palais ${ }^{46}$.

Revenant maintenant à l'association que peuvent présenter les tuiles en plomb, le relief dit du «palais royal » et la description de Zhou Daguan, nous constatons le souci constant de l'auteur d'indiquer la hiérarchisation de la société angkorienne et ses formalisations, tant dans les attributs et les insignes du pouvoir que dans le type d'habitat et ses modes de couverture. Nous avons aussi remarqué que les architectures figurées qui présentent une couverture métallique accueillaient principalement des personnages majeurs (royaux ou divins). Il est légitime de soupçonner chez ces reliefs une tendance à sublimer la réalité et à représenter « ce qu'on fait de mieux ». Il apparaît donc que, schématiquement, le luxe soit associé à la couverture métallique ${ }^{47}$. On ne s'étonnera donc pas de la contradiction apparente entre le relief du palais royal et la description de Zhou Daguan : toutes les couvertures représentées sur le relief semblent

44. Le nombre de cours varie suivant les auteurs et l'interprétation des vestiges situés dans la partie occidentale du palais. Ils s'accordent cependant sur les deux premières cours (Dumarçay, 1991, p. 40-41. Gaucher, 1996, p. 7).

45. Dans le cas d'Ayuthia par exemple, il est clair que la salle d'audience était située dans le palais, et qu'elle représentait dans ce palais le seul lieu accessible aux membres des Ambassades étrangères (Pelliot, 1951, p. 154 note 1).

46. Pelliot suggère par ailleurs cette localisation lorsqu'il précise que « la phrase [traitant des linteaux et colonnes] s'applique bien au palais lui-même et [qu'il] hésite à admettre qu'elle vise seulement les terrasses d'honneur ». La description relative aux tuiles en plomb, située avant cette phrase et après celle qui donne le périmètre du palais, concernerait donc aussi un pavillon situé dans l'enceinte même du palais.

47. Un fragment de tuile couvre-joints de terre cuite jaune auquel adhérait un mince morceau de feuille d'or a été dégagé dans nos sondages au perron nord. L'échantillon ne saurait cependant être suffisant pour attester l'existence de couverture de tuiles dorées à la feuille. 
en métal, alors que l'auteur chinois n'indique ce type de couverture que pour un édifice particulier. Il semble plus vraisemblable de suivre celui-ci et de conclure que le type de toiture en plomb ait été réservé à une partie privilégiée du palais.

\section{Des éléments de couverture en plomb au perron nord de la terrasse des Éléphants?}

Si les tuiles en plomb étaient réservées à une pièce du palais, comment la présence d'éléments du même type peut-elle s'expliquer dans nos sondages au perron nord de la terrasse des Éléphants ${ }^{48}$ ? Outre ce problème de localisation géographique, nous devons aussi nous interroger sur leur situation chronologique afin de préciser leur éventuelle association avec le palais royal du relief du Bayon ou avec celui décrit par Zhou Daguan. Que ces deux palais aient été situés au même emplacement, à savoir dans l'enceinte de ce qu'on appelle actuellement le «palais royal d'Angkor Thom », ne pose pas de doute particulier dans l'état actuel de nos connaissances et en l'attente des résultats des recherches archéologiques que l'EFEO y conduit sous la direction de J. Gaucher. Il reste que ces deux sources mentionnent probablement des palais différents qui ont pu se succéder dans cette même enceinte. Zhou Daguan fait évidemment référence au palais existant lors de son séjour en 1296. Il est plus délicat de dater celui qui a pu être représenté sur la galerie extérieure du Bayon. Nous suivrons pour cela l'opinion de B.-P. Groslier qui considère que le palais ayant servi de modèle est celui de Jayavarman VII, à la fin du XIIe siècle et plus précisément « vers 1183 1184 , en tout cas avant 1186 »(Groslier, 1973, p. 164). La datation des éléments métalliques dégagés à la terrasse des Éléphants coïnciderait-elle avec le passage de Zhou Daguan, ou avec le règne de Jayavarman VII ?

\section{Chronologie relative des états de la face occidentale du perron nord de la terrasse des Éléphants}

L'analyse des résultats des huit sondages réalisés dans la partie occidentale du perron nord de la terrasse des Éléphants est encore en cours et il serait prématuré de donner dans l'état actuel une synthèse détaillée des occupations successives de cette zone. Notons seulement ici qu'un jeu complexe de superpositions successives indique au moins quatre grandes séquences d'aménagement de la partie occidentale (cf. pl. 1). Un premier niveau anthropique est attesté par quelques rares vestiges de structures en latérite situées sous la base des gradins de latérite qui parementent l'angle nord-est de la douve du palais royal, gradins qui matérialisent pour une large part un second état d'occupation. Considérant les datations des gopuras du palais, et l'homogénéité de ceux-ci avec l'enceinte et sa douve, nous envisageons donc actuellement ce second état au début du XIe siècle. Les aménagements postérieurs montrent des remaniements importants où se succèdent en se mêlant deux phases principales. Le troisième état est caractérisé par un contrefort en latérite qui paremente - au moins — la moitié nord de la face occidentale du massif de la terrasse, et par un important système de canalisation et de drainage qui, depuis le nord de la terrasse du Roi lépreux, collecte les eaux de la

48. Ou encore, si les toitures de plomb mentionnées par Zhou Daguan correspondent aux pavillons qui dominaient les terrasses royales, pourquoi ne retrouver ces tuiles qu'au perron nord, qui plus est sur la face occidentale? 
terrasse des Éléphants pour les déverser dans les douves du palais royal. Bien que la logique spatiale de cet état reste encore en partie obscure, il semble devoir être rattaché aux reliefs orientaux de la terrasse des Éléphants et, plus précisément, au premier état de la terrasse du Roi lépreux daté des premières années du règne de Jayavarman VII. Un quatrième et dernier état est constitué par un réaménagement du troisième état, en particulier au sommet du perron, et la réalisation de gradins grossièrement construits sur la ruine de l'état antérieur et sur le comblement de la douve du palais royal. Il correspondrait à une réoccupation du site, probablement au XVIe siècle.

\section{Localisation des éléments dégagés}

Les éléments de couverture en plomb ont tous été mis au jour de part et d'autre et au pied du redent central du contrefort du troisième état. Ces objets ont été rencontrés dans deux contextes distincts.

Dans le premier, situé au nord-ouest du redent central (TP3W), 23 objets en plomb ont été dégagés, dont la majorité ${ }^{49}$ dans une poche de superficie réduite de remblais anthropiques contenant quelques fragments de feuilles de bronze, à quelques mètres du pied du contrefort, en contrebas de l'assise de réglage et sous un bloc de grès incomplet dont la sculpture inachevée de feuillages enroulés s'apparente à la période du Bayon. D'autre part, cette strate repose sur les traces d'un sol de grains de latérite que l'on suit jusqu'à la base des vestiges en latérite de la base d'un édifice à structure en bois (dans la berme entre TP1W et TP4W). Ces vestiges semblent contemporains des douves, et nettement antérieurs à une canalisation rattachée au troisième état. Ils marquent par ailleurs la limite nord contre laquelle s'appuie un niveau particulier légèrement plus élevé, rencontré dans le TP4W. Ce niveau correspond à une importante activité métallurgique, attestée par une forte densité de charbons mêlés à de nombreux creusets, fragments métalliques et scories. Il se poursuit vers le sud (TP2W) où il règne avec le gradin supérieur de la douve.

Dans un second contexte, au sud-ouest (TP5W, TP6W et TP8W), 63 éléments ont été dégagés d'une importante couche de comblement artificiel de la douve du palais royal, proche des gradins inférieurs. Bien que le matériel associé ne soit pas encore analysé, on note que cette strate s'est révélée très riche: outre les éléments de plomb, elle contenait divers objets métalliques (fer et bronze), plusieurs perles et une importante concentration de tessons et de fragments de tuiles de pâte jaune sans couverte ou grise à glaçure verte, dans un environnement sableux à fortes concrétions latéritiques présentant par endroit de nombreux charbons. Forcément postérieure à la douve du palais royal, ce comblement est antérieur à celui des superstructures du troisième état, et semble correspondre au niveau d'activité métallurgique mentionné précédemment ${ }^{50}$. La similitude des objets de plomb avec ceux dégagés dans TP3W confirme par ailleurs cette position dans les séquences d'aménagement.

49. Quelques fragments altérés ou mal fondus ont aussi été dégagés dans la même zone, mais l'un dans la partie supérieure du remblai situé derrière le contrefort, l'autre à l'extérieur dans un recoin d'une des premières assises du contrefort. Leurs présences en ces lieux peuvent s'expliquer par une réfection du sommet du mur du contrefort et l'utilisation des sols environnants comme remblai. Toutes les données nécessaires pour s'en assurer n'ont cependant pas encore été collectées. Un fragment de plomb de petite taille et de fonction indéterminée a d'ailleurs été trouvé isolé dans TP4W, dans une couche supérieure.

50. Il serait difficile d'interpréter les couches comportant des tuiles en plomb comme faisant partie d'un important remblaiement général réalisé par Jayavarman VII en préalable à la construction du contrefort du troisième état. Cette hypothèse se fonderait sur des tuiles métalliques ayant échappé successivement au sac cham puis, mêlées aux décombres, à la réutilisation lors de leur transport 


\section{Essai d'interprétation}

La localisation des éléments de couverture en plomb mis au jour à la terrasse des Éléphants empêche dès à présent d'y voir ceux remarqués par Zhou Daguan sur le palais de Çrîndravarman. De même, on ne peut établir de lien de contemporanéité avec les six tortues en plomb qui participaient au dense réseau de dépôts de fondation mis au jour sous l'extrémité orientale de la face est, cette extension datant - au plus tôt - de la seconde moitié du XIIIe siècle (cf. infra p. 383-384 et p. 402-407). Par contre, il reste possible que ces tortues aient été réalisées en réemployant des tuiles en plomb mises au jour à l'occasion de réaménagements postérieurs de la face occidentale ${ }^{51}$.

Il n'en reste pas moins que les données recueillies - caractéristiques et utilisation exceptionnelle des tuiles en plomb, localisation spatiale et chronologique - se heurtent à la complexité du détail des réaménagements qui se sont succédés sur ce même espace. Elles peuvent suggérer des explications partielles assez contradictoires. Celle que nous proposerons tente de synthétiser ces diverses informations mais demeure générale faute de recherches complémentaires dans les environs. Les sondages ont été réalisés, rappelons-le, dans le but d'observer les structures de la face occidentale du perron, dans le cadre de leur restauration, et ils ne permettent qu'une vision ponctuelle insuffisante pour dégager les logiques d'occupation de cette zone.

Notre interprétation s'appuie en premier lieu sur les caractéristiques des objets de plomb découverts. Nous avons indiqué plus haut certaines déformations pouvant suggérer un incendie, ou plus précisément une surchauffe, et des bavures et des traces de troncatures qui évoquent des éléments non "finis » ou en cours de réemploi. La présence en un même lieu d'une variété si importante d'objets, y compris des éléments de tuyauterie, fournit aussi un indice en faveur d'une collecte de matériaux en vue d'une production ${ }^{52}$. Bien que nul moule n'ait été retrouvé, les traces d'une activité métallurgique dans un niveau associé voisin permettent d'avancer la présence d'un atelier de fonte au bord des gradins de la douve. Cet atelier, au vu des fragments métalliques qui y ont été dégagés - bien que nos sondages n'en ont entamé qu'une frange réduite - a été le lieu d'une métallurgie associant fer, plomb et, éventuellement, bronze ${ }^{53}$. C'est donc cette activité variée qui expliquerait essentiellement la présence

jusqu'au perron nord de la terrasse des Éléphants. Ce point serait particulièrement fortuit si l'on considère que le remblaiement, faute de pelleteuse mécanique, devait être réalisé par petites quantités mais par de nombreux ouvriers, ou du moins de multiples allers et retours. Que ces nombreux éléments métalliques aient échappé à leur attention et n'aient pas été réutilisés serait troublant. Seule l'application d'un ordre strict de ne rien récupérer dans ces remblais - afin d'oublier à tout jamais un épisode infamant? - expliquerait la survie des tuiles métalliques, mais serait un exemple exceptionnel et complètement contradictoire avec la tradition répétée de réutilisation. Par ailleurs, la présence au fond des douves des tuiles métalliques et du remblai conséquent dont elles ont été dégagées, serait problématique même en considérant un improbable accident en cours de chantier - un glissement du remblai par exemple.

51. On constate par exemple que les éléments en plomb provenant de TP3W étaient situés (en $1996)$ à une très faible profondeur $(70 \mathrm{~cm})$ et que leur niveau peut avoir été atteint à l'occasion d'une réfection du sommet du contrefort. De même, la périphérie nord de la strate présentant une activité métallurgique montre qu'elle a été coupée lors des aménagements postérieurs de la terrasse.

52. Il est cependant tout à fait envisageable que des éléments de couverture de types différents, en particulier pour les antéfixes, ont été employés sur un même édifice, permettant ainsi soit d'accuser des effets perspectifs, soit de souligner les hiérarchies des corps de toiture. Notons encore que seuls les antéfixes de série $C$ présentent tous des bavures de fonte qui pourraient indiquer qu'il s'agisse d'une production nouvelle. Nous n'avons pas trouvé de relation particulièrement signifiante entre les divers types d'éléments de plomb et leurs localisations ou leurs positions dans les stratigraphies. Tout au plus nous noterons que TP3W présentait trois antéfixes identifiables, tous de série $\mathrm{A}$.

53. Au moment d'achever ces lignes, un fragment de feuille de plomb, des débris de bronze et quelques scories ont été dégagés dans le fond d'un trou de poteau de la structure du troisième état qui 
des tuiles dans nos sondages. Rappelons, pour la coïncidence, qu'au début du $\mathrm{XX}^{\mathrm{e}}$ siècle, à $\mathrm{Phnom}$ Penh, les ateliers royaux d'orfèvrerie étaient « situés à proximité et au nord du palais » (Marchal, 1939, p. 133).

L'analyse stratigraphique indique qu'une première structure, peut-être associée aux gradins de la douve (une première phase du second état), fut détruite, partiellement démontée et ses fondations recouvertes par un premier remblaiement, sur lequel s'est alors installé un atelier métallurgique. Cet atelier aurait donc été utilisé lors d'une seconde phase du second état, assez longue si l'on en juge par l'épaisseur de la couche de comblement de la douve et par les superpositions de fosses. Une indécision subsiste encore quant à la période de cessation exacte de son activité: avant la construction du palais de Jayavarman VII ou aussitôt après son achèvement pour laisser place à la construction de la terrasse des Éléphants? Dans ce dernier cas, les tuiles retrouvées proviendraient, pour les plus tardives, tantôt de la récupération sur les vestiges ruinés de l'habitation principale de «l'usurpateur » Tribhuvanâdityavarman ou de celle de son infortuné prédécesseur Yaśovarman II (Cœdès, 1989a, p. 299-300), tantôt d'une nouvelle production destinée à orner le pavillon de Jayavarman VII représenté sur le relief du Bayon. Malgré cette imprécision, nous avons cependant ici le témoin de l'utilisation, au moins un siècle avant le séjour de Zhou Daguan, et dès cette époque déjà parfaitement maîtrisée, de couvertures en plomb aux formes extrêmement riches et variées.

L'état de connaissances que nous venons de dresser et les réflexions abordées gardent un caractère provisoire, car les travaux ne sont pas achevés au perron nord de la terrasse des Éléphants, et les tuiles en plomb recueillies ne constituent qu'un premier lot dont on peut espérer trouver dans l'avenir des complémentaires ailleurs, en particulier au palais royal. Plusieurs aspects ont cependant pu être dégagés sur les couvertures en plomb. En premier lieu se confirme l'existence de deux types de couverture, l'un avec des éléments plats à pureau en losange, l'autre avec un système «classique » de tuiles canal et couvre-joints. Pour ce dernier, on remarque des détails similaires à ceux présentés par les éléments en terre cuite. De même, les motifs des antéfixes, hormis quelques masques originaux ( $\mathrm{F}$ et $\mathrm{I}$ ), reprennent des thèmes représentés sur des tuiles d'about de terre cuite. Ce constat offre une nouvelle lecture de certaines architectures figurées sur les bas-reliefs, d'autant qu'aucune répercussion structurelle ne semble être induite par les couvertures en plomb, sinon qu'elles peuvent s'appliquer aussi à des édifices «légers", souvent qualifiés de «temporaires». Nous avons d'ailleurs cru bon de voir dans les représentations d'édifices à pureau losange, qui abritent exclusivement des personnages d'importance, une confirmation indirecte de l'usage restrictif de la couverture en plomb rapporté par Zhou Daguan. Les éléments de couverture en plomb découverts à l'ouest du perron nord de la terrasse des Éléphants, en dehors donc d'un contexte d'architectures palatiales, tireraient leur origine de l'existence en ce lieu d'un atelier métallurgique dont les indications recueillies à l'heure actuelle n'autorisent qu'une datation large - du XIe à la fin du XIIe siècle. La diversité des objets mis au jour suggère par ailleurs que cet atelier situé en bordure des douves du palais, avait une production variée vraisemblablement fondée sur du réemploi. Dans le cadre plus large

borde les gradins supérieurs de la douve. Leur niveau coïncide avec celui de l'activité métallurgique et indique que cet atelier s'étendait jusqu'au premier gradin qui faisait office de margelle. 
de l'emploi du plomb à Angkor, le métal pourrait provenir de quelques sites de galènes proches d'Angkor ou situés plus loin dans l'empire khmer. L'importation du plomb à partir du réseau d'échanges Sud-Est asiatique reste aussi envisageable, d'autant que l'emploi de ce métal semble avoir été particulièrement rare à Angkor, réservé aux temples et aux palais.

\section{BIBLIOGRAPHIE}

\section{COLLECTIF}

1982 «L'art de la couverture », L'art du couvreur, t. II et III, Encyclopédie des métiers, Librairie du Compagnonnage, Paris.

BEZACIER, Louis

1972 Le Viêt-Nam, Manuel d'archéologie d'Extrême-Orient, t. II, Paris.

BOISSELIER, Jean

1966 Le Cambodge, Manuel d'archéologie d'Extrême-Orient, t. I, Paris.

1967 «Notes sur l'art du bronze dans l'ancien Cambodge », Artibus Asiae XXIX, n 4 ,

CEEDÈs, George Paris, p. 275-334.

1952 Inscriptions du Cambodge, EFEO, t. IV, Paris.

1989a Les états hindouisés d'Indochine et d'Indonésie, De Broccard, Paris.

1989b Articles sur le Pays Khmer, Réimpression de l'EFEO, t. I, Paris.

1992 Articles sur le Pays Khmer, Réimpression de l'EFEO, t. II, Paris.

CCEDĖS, George, FINOT, Louis et GOLOUBEW, Victor

1932 «e temple d'Angkor Vat », Mémoires archéologiques II, EFEO, Paris, 3 vol..

COURBIN, Paul

1988 Les fouilles de Sra Srang, EFEO, Paris.

DAGENS, Bruno

1970 Mayamata, traité sanskrit d'architecture, IFI, t. I, Pondichéry.

1976 Mayamata, traité sanskrit d'architecture, IFI, t. II, Pondichéry.

DOTTIN, Olivier

1971 Géologie et mines du Cambodge, Document dactylographié, Phnom Penh.

DUMARÇAY, Jacques

1973 «Charpentes et tuiles khmères », Mémoires archéologiques VIII, EFEO, Paris.

1982 «Notes d'architecture javanaise et khmère », BEFEO LXXI, Paris, p. 87-146.

1991 The palaces of South-East Asia. Architecture and customs, Oxford University Press, Singapour.

GAUCHER, Jacques

1996 Etudes archéologiques à Angkor. De Yasodharapura à Angkor Thom, EFEO, rapport.

GROSLIER, Bernard-Philippe

1958 Angkor et le Cambodge au XVIe siècle d'après les sources portugaises et espagnoles, PUF, Paris.

1969 « La Terrasse du Roi Lépreux », Nokor Khmer, n¹, Phnom Penh, p. 18-33.

1973 «Inscriptions du Bayon », Mémoires archéologiques III-2, EFEO, Paris. 
1983 Indochine, Carrefour des arts, Albin Michel, Paris.

GROSLIER, Georges

1923 «L'art du bronze au Cambodge », Arts et Archéologie Khmers, t. I, fasc.4, Paris, p. 413-423.

1930 «La fin d'une tradition d'art : les pagodes cambodgiennes et le ciment armé », L'Illustration, $\mathrm{n}^{\circ} 4532$, janv., Paris, p. 50-53.

HANKS, Jane et LUCIEN, M.

1988 « The gabled roofs of thai temples, an adventure in tracing Chinese influences », HOWITZ, Pensak Journal of Siam Society, 76, Bangkok, p. 202-216.

1977 «Two ancient shipwrecks in the Gulf of Thailand: a report on archaeological investigations », Journal of Siam Society, 65/2, Bangkok, p. 1-22. Publié in Thai pottery and ceramics, The Siam Society, Bangkok, 1986, p. 283-305.

LOMBARD, Denys

1967 Le sultanat d'Atjéh au temps d'Iskandar Muda, 1607-1636, EFEO, Paris.

1990 Le carrefour javanais, Essai d'histoire globale, EHESS, 3 vol., Paris.

LEVY, Paul

1943 Recherches préhistoriques dans la région de Mlu Prei, EFEO, Hanoi.

MALLERET, Louis

1959 L'archéologie du delta du Mékong, L'exploration archéologique et les fouilles d'Oc-éo, EFEO, t. I, 2 vol., Paris.

1960 L'archéologie du delta du Mékong, La civilisation matérielle d'Oc-éo, EFEO, t. II, 2 vol., Paris.

1962 L'archéologie du delta du Mékong, La culture du Fou-nan, EFEO, t. III, 2 vol., Paris.

1963 L'archéologie du delta du Mékong, Le Cisbassac, EFEO, t. IV, 1 vol., Paris.

MARCHAL, Henri

1939 La collection khmère, EFEO, Hanoi.

1955 «Modifications successives de la partie Nord de la terrasse des Éléphants d'Angkor Thom », BEFEO XLVII, Paris, p. 617-620.

PARMENTIER, Henri

1914 «L'architecture interprétée dans les bas-reliefs du Cambodge », BEFEO XIV, Hanoi, p. 1-28.

1918 Inventaire descriptif des monuments cams de l'Annam, EFEO, 2 vol., Paris.

PELLIOT, Paul

1903 «e Fou-nan », BEFEO III, Hanoi, p. 248-303.

1951 Mémoires sur les coutumes du Cambodge de Tcheou Ta-kouan, AdrienMaisonneuve, Paris.

POTTIER, Christophe

1994 «Éléments de couverture mis au jour au Prasat Phanom Wan », Recherches nouvelles sur le Cambodge, EFEO, Paris, p. 297-313.

1996 «Un réseau de dépôts de fondation mis au jour au perron nord de la terrasse des Éléphants (Angkor Thom) », Actes du Colloque international sur la khmerologie, 26-30 août 1996, Phnom Penh (à paraître).

THIERRY, Solange

1984 Le Popil : objet rituel cambodgien, Cedoreck, Paris.

YANG, Baoyun

1994 «Nouvelles études sur l'ouvrage de Zhou Daguan », Recherches nouvelles sur le Cambodge, EFEO, Paris, p. 227-234. 


\begin{tabular}{|c|c|c|c|c|c|c|c|c|c|c|c|}
\hline \multicolumn{12}{|c|}{ Tuiles canal et couvre-joints } \\
\hline & TP & Type & L & $\begin{array}{l}\text { larg. } \\
\text { max }\end{array}$ & $\begin{array}{c}\text { larg. } \\
\mathrm{min}\end{array}$ & Ep. & Pds g & $\begin{array}{c}\text { barrette } \\
\text { ou téton / } \\
\text { base }\end{array}$ & pureau & $\begin{array}{c}\mathrm{H.} \\
\text { bords }\end{array}$ & Remarques \\
\hline 1 & TP5W & canal & 310 & 245 & 225 & 3,8 & 1870 & 203 & 0,65 & 40 & $\begin{array}{l}\text { déformée sur le lattis: largeur } \\
\text { lattis } 6 \mathrm{~cm}\end{array}$ \\
\hline 6 & TP5W & canal & 285 & 196 & 187 & 4,4 & 1180 & 195 & 0,68 & 50 & \\
\hline 7 & TP5W & canal & 305 & 190 & 175 & 3,2 & 1120 & 165 & 0,54 & 45 & \\
\hline 11 & TP5W & canal & 267 & 205 & 195 & 3 & 1080 & 158 & 0,59 & 40 & \\
\hline 30 & TP3W & canal & 157 & 175 & 0 & 4,1 & 500 & 0 & 0,00 & 35 & fragment altéré \\
\hline 34 & TP5W & canal & 280 & 240 & 234 & 4,5 & 1650 & 210 & 0,75 & 40 & \\
\hline 35 & TP5W & canal & 305 & 215 & 190 & 4,5 & 1670 & 183 & 0,60 & 40 & \\
\hline 55 & TP6W & canal & 277 & 203 & 190 & 4 & 1580 & 194 & 0,70 & 35 & \\
\hline 95 & TP8W & canal & 260 & 197 & 190 & 3,8 & 1420 & 160 & 0,62 & 37 & $\begin{array}{l}\text { tuile canal de noue ? ou du } \\
\text { moins un angle légèrement } \\
\text { tronqué }\end{array}$ \\
\hline 96 & TP8W & canal & 225 & 130 & 87 & 3 & 750 & & & 45 & tuile canal de noue? \\
\hline 2 & TP5W & couvre-joints & 335 & 235 & 215 & 2,7 & 1680 & 155 & 0,46 & 0 & $\begin{array}{l}\text { traces de moulage surprenantes à } \\
\text { l'intérieur }\end{array}$ \\
\hline 9 & TP5W & couvre-joints & 275 & 225 & 195 & 3,5 & 1560 & 100 & 0,36 & 0 & \\
\hline 22 & TP5W & couvre-joints & 265 & 210 & 187 & 4,3 & 1500 & 165 & 0,62 & 0 & \\
\hline 29 & TP6W & couvre-joints & 342 & 220 & 215 & 3,7 & 1650 & 170 & 0,50 & 0 & téton au centre \\
\hline 40 & TP6W & couvre-joints & 250 & 214 & 197 & 3,1 & 1040 & 116 & 0,46 & 0 & \\
\hline 98 & TP8W & couvre-joints & 292 & 215 & 192 & 3,7 & 1380 & 200 & 0,68 & & $\begin{array}{l}\text { ancienne tuile canal avec } \\
\text { soudure d'un téton? }\end{array}$ \\
\hline 8 & TP5W & couvre-joints & 280 & 225 & 205 & 3,5 & 1650 & 90 & 0,32 & 0 & coin abattu pour noue à gauche \\
\hline
\end{tabular}

Tableau 1: Tuiles canal et couvre-joints 


\begin{tabular}{|c|c|c|c|c|c|c|c|c|c|c|}
\hline \multicolumn{11}{|c|}{ Antéfixes } \\
\hline & $\mathbf{T P}$ & \begin{tabular}{c|} 
Série \\
masque
\end{tabular} & $\begin{array}{l}\text { Hauteur } \\
\text { masque }\end{array}$ & $\begin{array}{l}\text { larg. } \\
\max \end{array}$ & $\begin{array}{l}\text { larg. } \\
\text { min }\end{array}$ & Ep. & Pds g & $\begin{array}{l}\text { larg. } \\
\text { patte }\end{array}$ & $\begin{array}{l}\text { long. } \\
\text { patte }\end{array}$ & Remarques \\
\hline 48 & TP5W & A & 122 & 160 & 126 & 5 & 540 & 40 & 180 & \\
\hline 57 & TP5W & A & 118 & 141 & 114 & 4,1 & 530 & 35 & 175 & avec petit trou sur patte d'accroche \\
\hline 70 & TP3W & A & 120 & 145 & 0 & 4,2 & 480 & 37 & 190 & altéré ou mal fondu, trou dans la \\
\hline 86 & TP3 W & A & 111 & 151 & 118 & 3,2 & 550 & ind. & 165 & $\begin{array}{l}\text { en deux morceaux, masque replié sur } \\
\text { lui-même, très probablement un trou } \\
\text { dans la patte d'accroche au niveau de } \\
\text { la cassure. }\end{array}$ \\
\hline 87 & TP3 W & A & 123 & 141 & 113 & 4,7 & 660 & 36 & 180 & $\begin{array}{l}\text { pas de trou mais queue de patte } \\
\text { probablement repliée }\end{array}$ \\
\hline 94 & TP8W & A & 115 & 135 & 110 & 5,1 & 580 & 31 & 180 & angle droit cassé \\
\hline 56 & TP5W & B & 120 & 137 & 105 & 3,6 & 900 & 36 & 214 & \\
\hline 24 & TP6W & $\mathrm{C}$ & 123 & 140 & 110 & 6,2 & 800 & 23 & 217 & $\begin{array}{l}\text { flammèches plus pointues complètes, } \\
\text { bavure en bout de patte d'accroche }\end{array}$ \\
\hline 46 & TP6W & $\mathrm{C}$ & 130 & 156 & 110 & 4,6 & 780 & 30 & 223 & $\begin{array}{l}\text { avec bavure en queue de patte } \\
\text { d'accroche et masque }\end{array}$ \\
\hline 50 & TP5W & $\mathrm{C}$ & 117 & 136 & 112 & 3,9 & 680 & 27 & 168 & angle droit masque cassé \\
\hline 53 & TP5W & $\mathrm{C}$ & 122 & 126 & 105 & 3,2 & 600 & 25 & 204 & patte étroite \\
\hline 59 & TP5W & $\mathrm{C}$ & 123 & 122 & 110 & 4,6 & 600 & 24 & 220 & \\
\hline 60 & TP5W & $\mathrm{C}$ & 122 & 135 & 108 & 3,7 & 600 & 27 & 200 & \\
\hline 15 & TP5 W & D & 118 & 170 & 105 & 2,6 & 810 & 40 & 238 & tenon en pointe ep. 7,8 \\
\hline 42 & TP5W & D & 125 & 160 & 110 & 4 & 650 & 45 & 200 & \\
\hline 62 & TP6W & D & 121 & 158 & 105 & 5,2 & 760 & 42 & 180 & \\
\hline 93 & TP8W & D & 120 & 165 & 102 & 4,5 & 670 & 41 & 202 & trace de refonte, réparation? \\
\hline 97 & TP5W & $\mathrm{D}$ & 115 & 160 & 100 & 2,9 & 820 & 40 & 210 & couverte orange rouge? \\
\hline 61 & TP6W & $\mathrm{E}$ & 121 & 172 & 113 & 3,9 & 750 & 45 & 200 & \\
\hline 91 & TP8W & $\mathrm{F}$ & 105 & 154 & 100 & 5,7 & 810 & 49 & 206 & sommet du masque cassé \\
\hline 33 & TP5W & G & 150 & 175 & 115 & 5,3 & 880 & 40 & 25 & patte cassée \\
\hline 54 & TP6W & G & 130 & 163 & 105 & 2,3 & 940 & 45 & 223 & rainures sur la patte d'accroche \\
\hline 4 & TP5W & $\mathrm{H}$ & 135 & 133 & 85 & 5,5 & 840 & 48 & 195 & \\
\hline 41 & TP5W & I & 160 & 120 & 58 & 4,6 & 990 & 38 & 186 & $\begin{array}{l}\text { avec en bout de patte une petite } \\
\text { barrette pour accroche sur lattis. }\end{array}$ \\
\hline 49 & TP5W & $\mathrm{I}$ & 162 & 98 & 66 & 6,1 & 850 & 39 & 195 & $\begin{array}{l}\text { avec en bout de patte une petite } \\
\text { barrette pour accroche sur lattis. }\end{array}$ \\
\hline 58 & TP5W & I & 162 & 139 & 65 & 5,5 & 1220 & 44 & 189 & $\begin{array}{l}\text { avec en bout de patte une petite } \\
\text { barrette pour accroche sur lattis. }\end{array}$ \\
\hline 10 & TP5W & ind. & 200 & 33 & 0 & 6,4 & 340 & 33 & 200 & $\begin{array}{l}\text { seulement un fgt de patte d'accroche } \\
\text { avec rainures }\end{array}$ \\
\hline 27 & TP6W & ind. & 65 & 0 & 0 & 3,4 & 30 & 0 & 0 & $\begin{array}{l}\text { fragment de flammèche d'angle de } \\
\text { masque }\end{array}$ \\
\hline 63 & TP6W & ind. & 92 & 40 & 0 & 2,7 & 100 & 0 & 0 & $\begin{array}{l}\text { fragment plat de patte d'accroche avec } \\
\text { rainures parallèles d'accroche }\end{array}$ \\
\hline 76 & TP3 W & ind. & 60 & 38 & 0 & 3,8 & 90 & 0 & 0 & $\begin{array}{l}\text { fragment de patte d'accroche avec un } \\
\text { bout de masaue reolié }\end{array}$ \\
\hline
\end{tabular}

Tableau 2: Antéfixes 


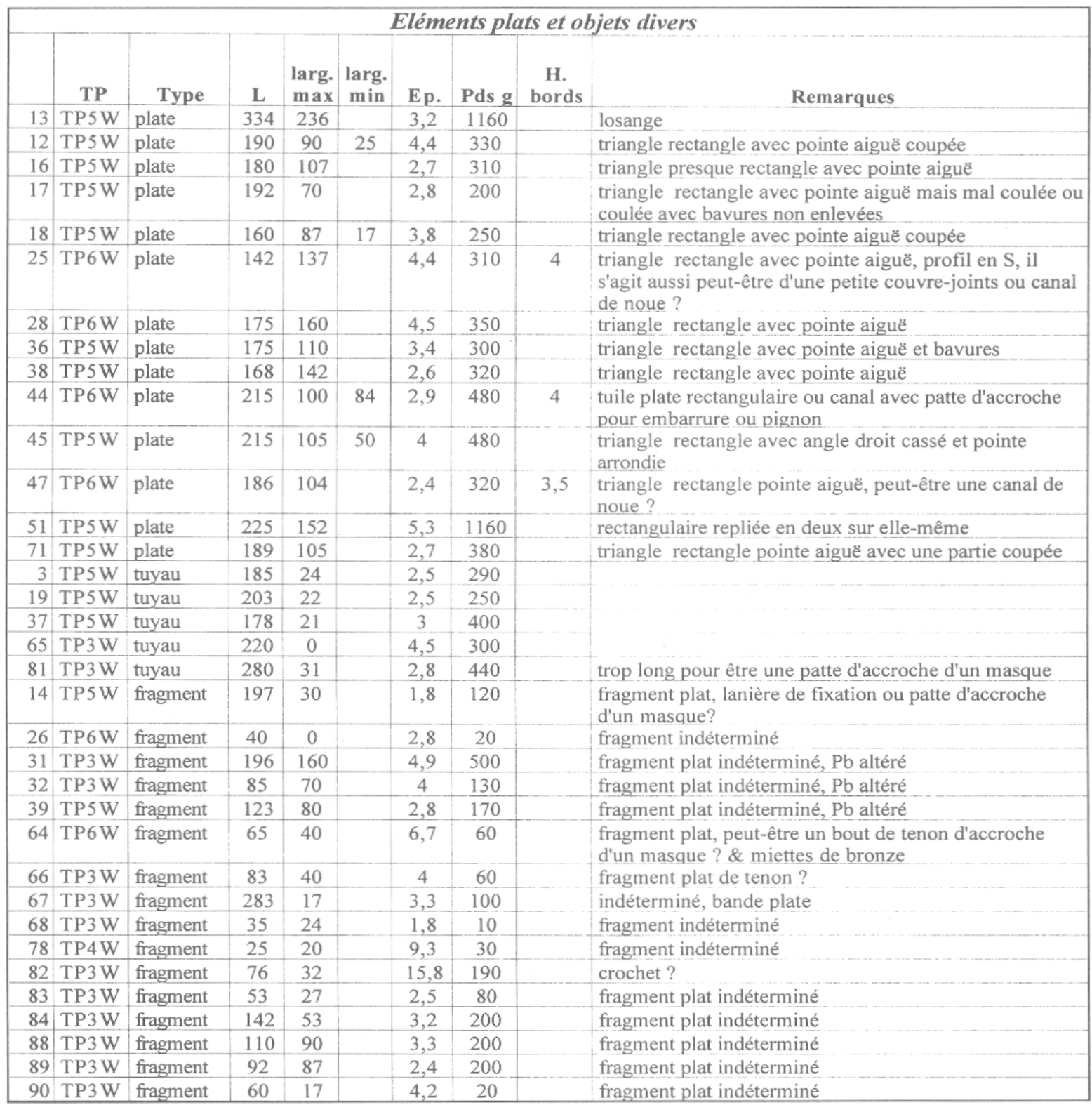

Tableau 3: Éléments plats et objets divers 


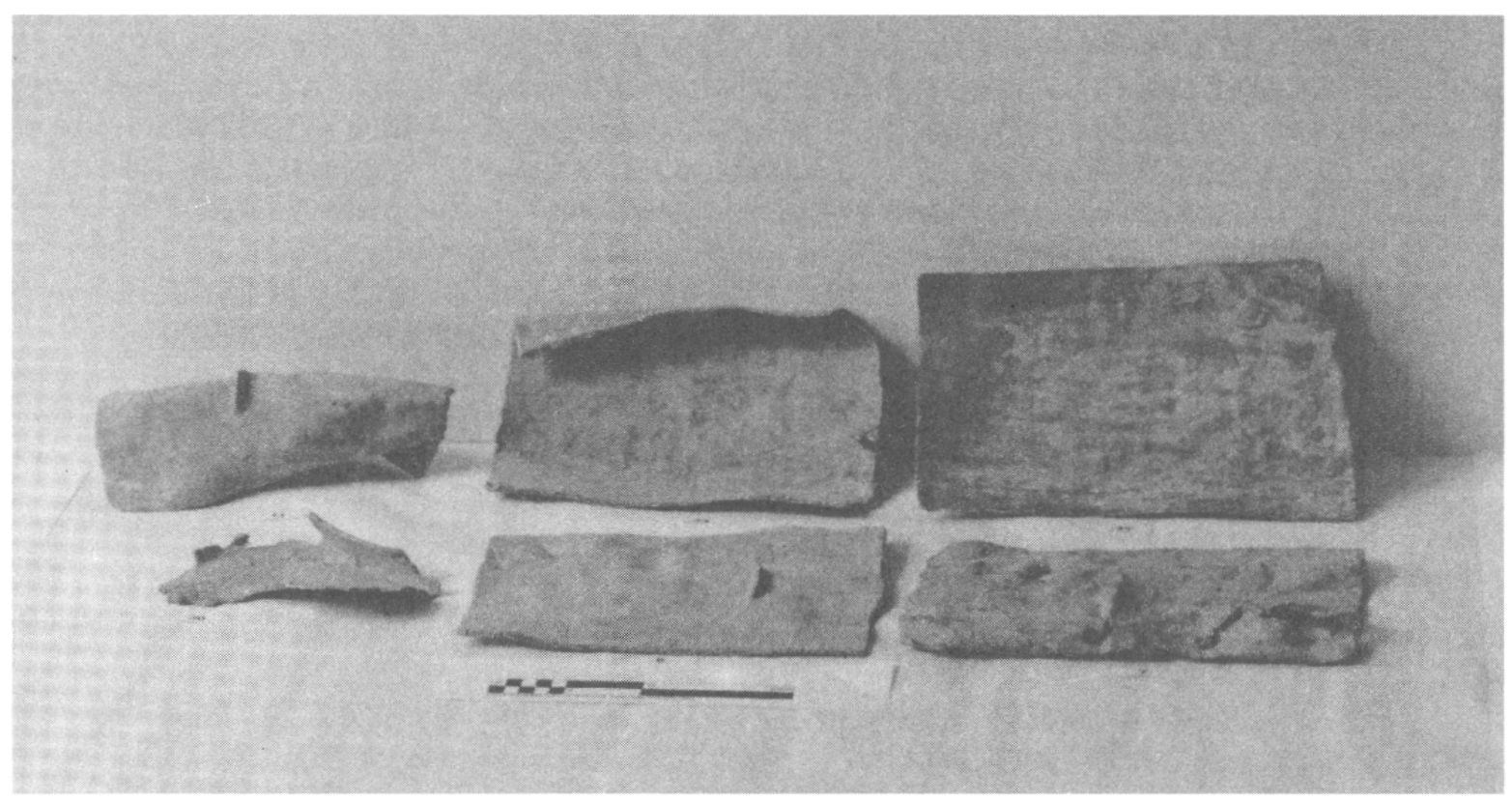

Photo 1 : Tuiles canal $n^{\circ} 11,34,35,30,6$ et 7

(Les numérotations correspondent aux objets lus de gauche à droite et de haut en bas)

Photo 2 : Tuiles couvre-joints $n^{\circ} 8$ et 98

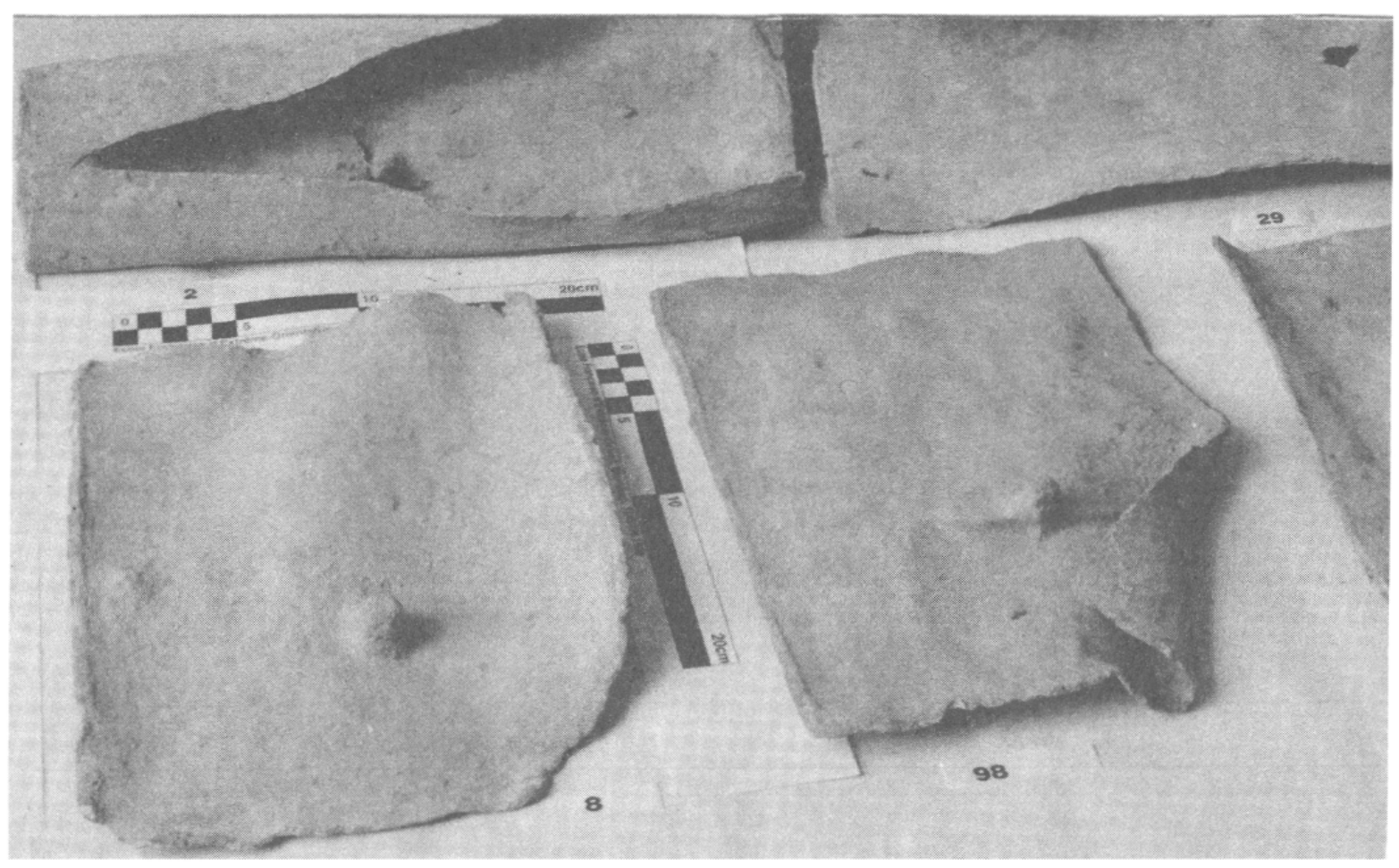




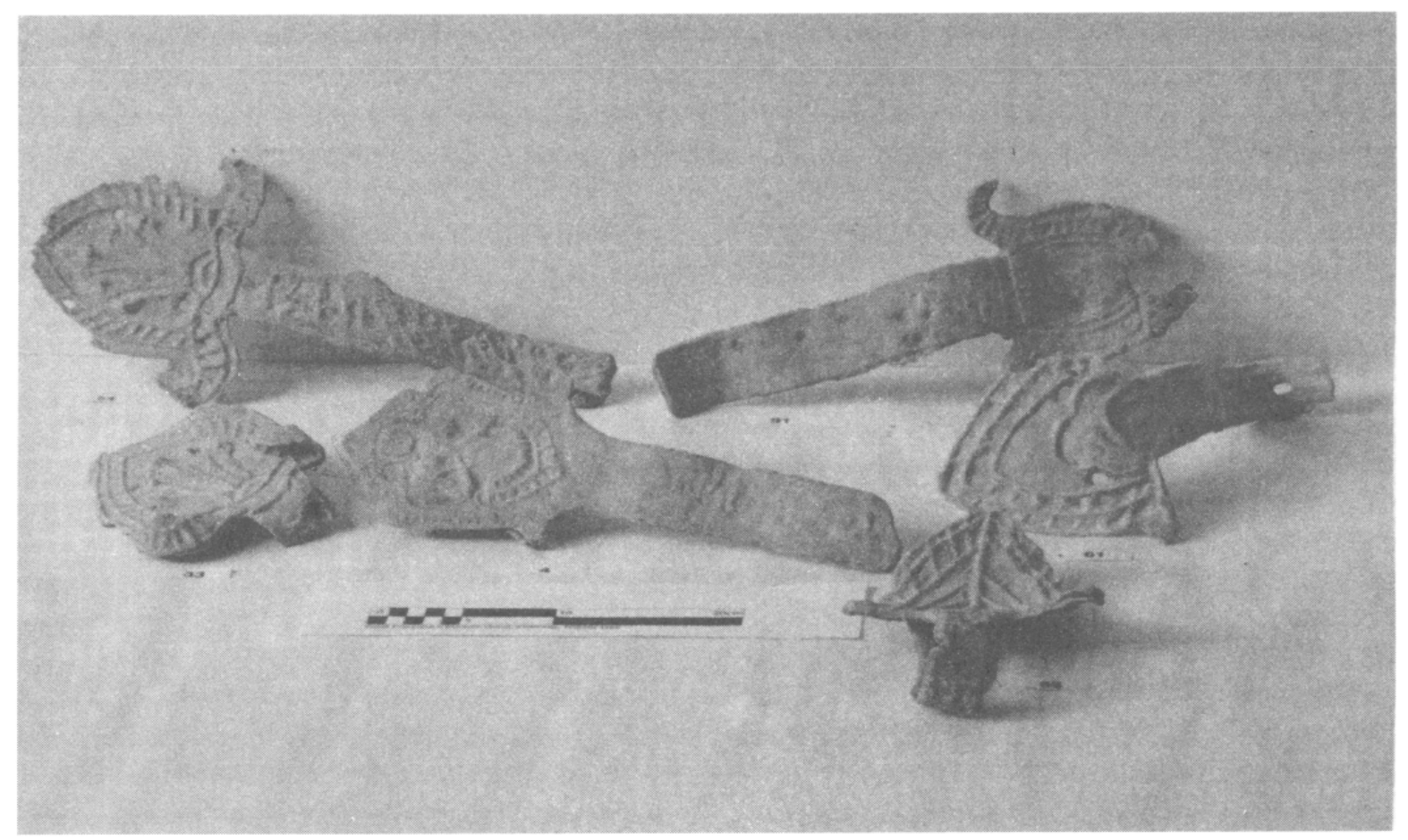

Photo 3 : Antéfixes de série $\mathrm{G} \mathrm{n}^{\circ} 54, \mathrm{~F} \mathrm{n}^{\circ} 91, \mathrm{G} \mathrm{n}^{\circ} 33, \mathrm{H} \mathrm{n}^{\circ} 4, \mathrm{~B} \mathrm{n}^{\circ} 56$ et $\mathrm{E} \mathrm{n}^{\circ} 61$

Photo 4 : Antéfixe de série I $n^{\circ} 58$

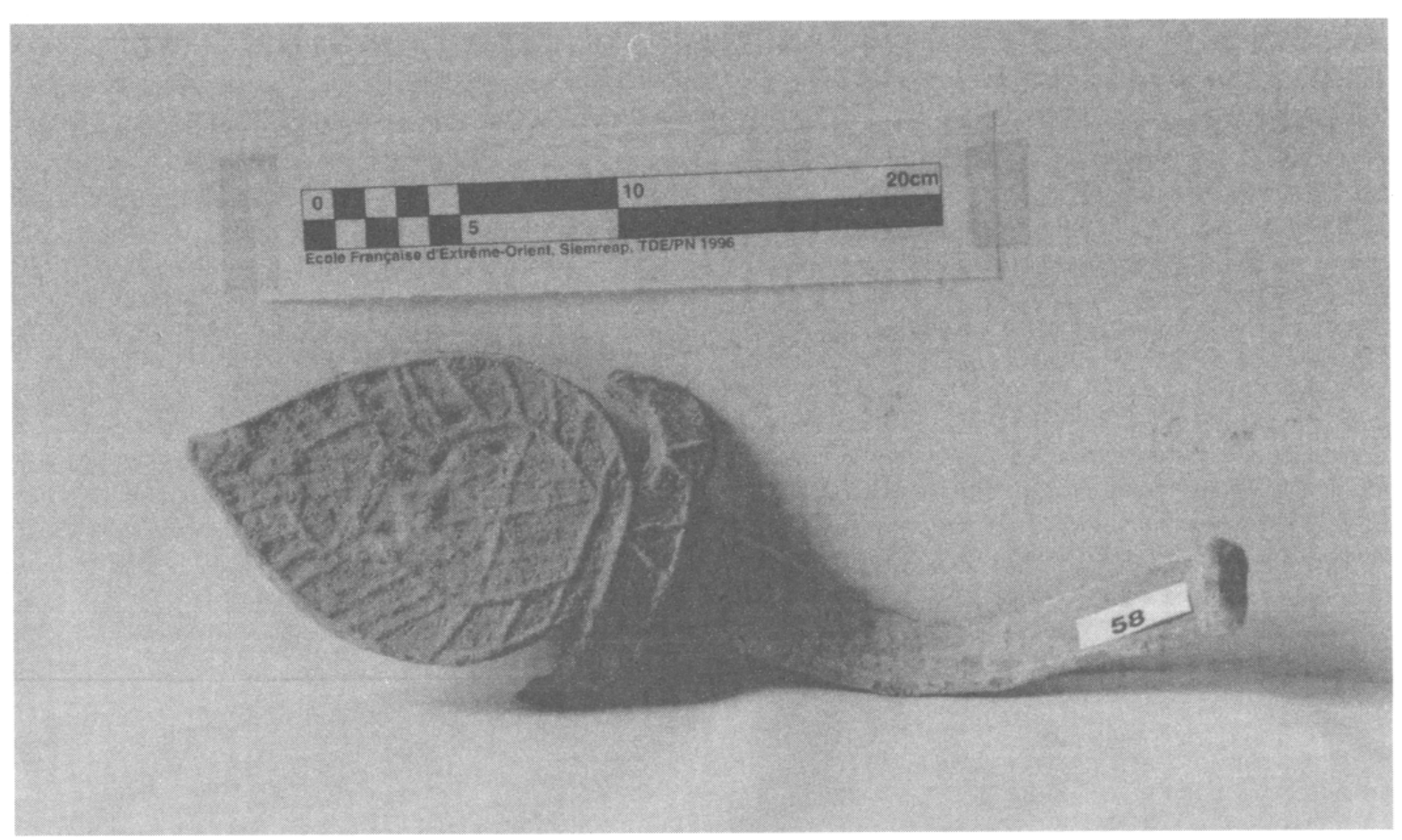

BULLETIN DE L'ÉCOLE FRANÇAISE D'EXTRÊME-ORIENT 


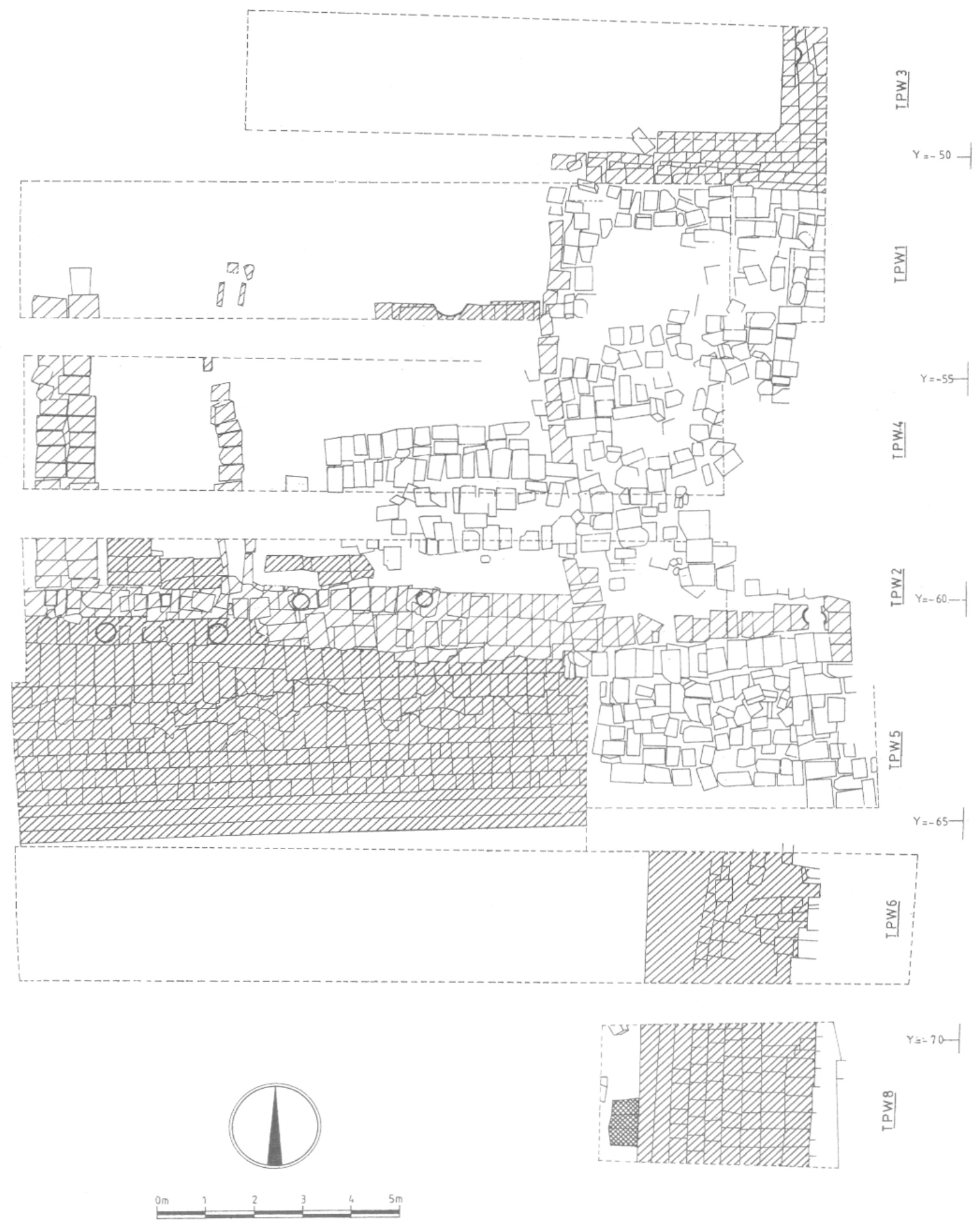

Planche 1: Plan d'ensemble des sondages et des structures dégagées sur la face ouest du perron nord de la terrasse des Éléphants. Quatre séquences d'aménagement: état 1, hachures croisées sombres; état 2, hachures sombres; état 3 , hachures claires; état 4 , blanc. 

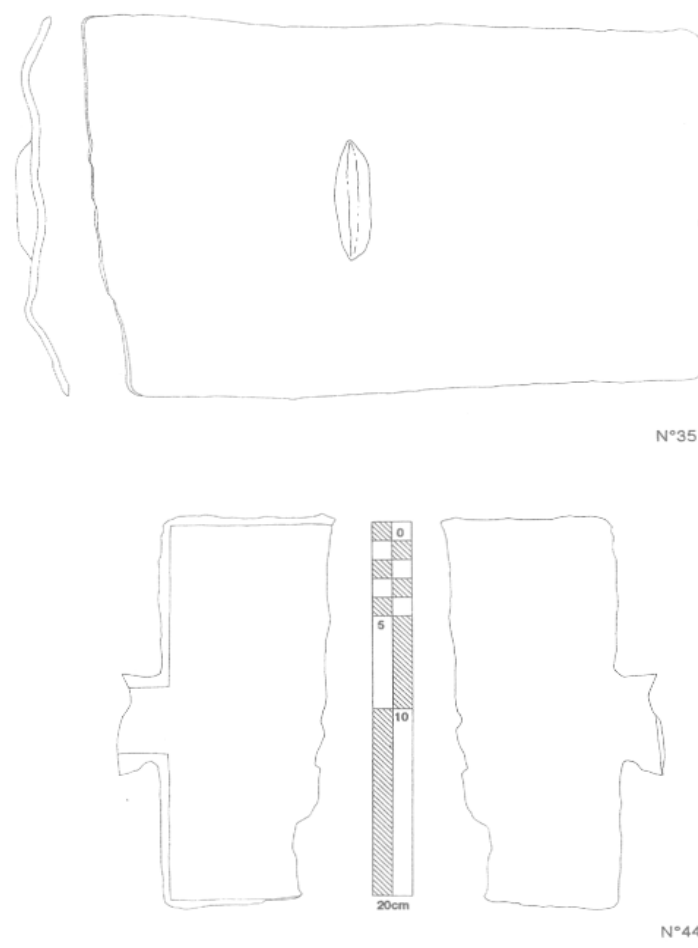

Planche 2: Tuile canal $n^{\circ} 35$ et élément plat à coupe spéciale $n^{\circ} 44$
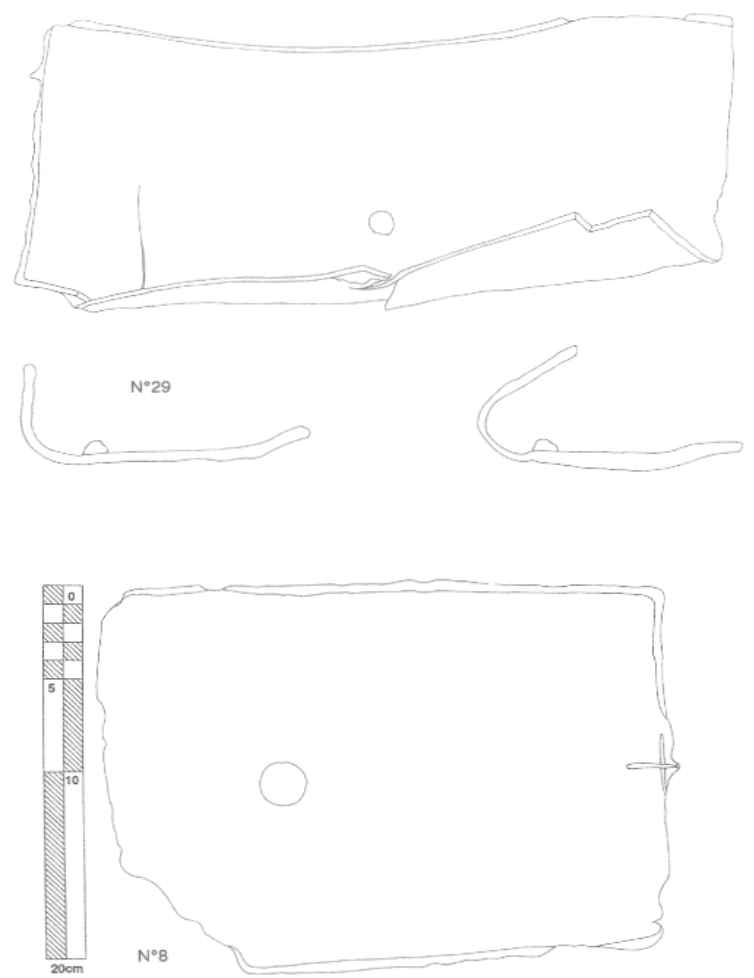

Planche 3: Tuile couvre-joints $n^{\circ} 29$ et tuile couvre-joints $n^{\circ} 8$ 

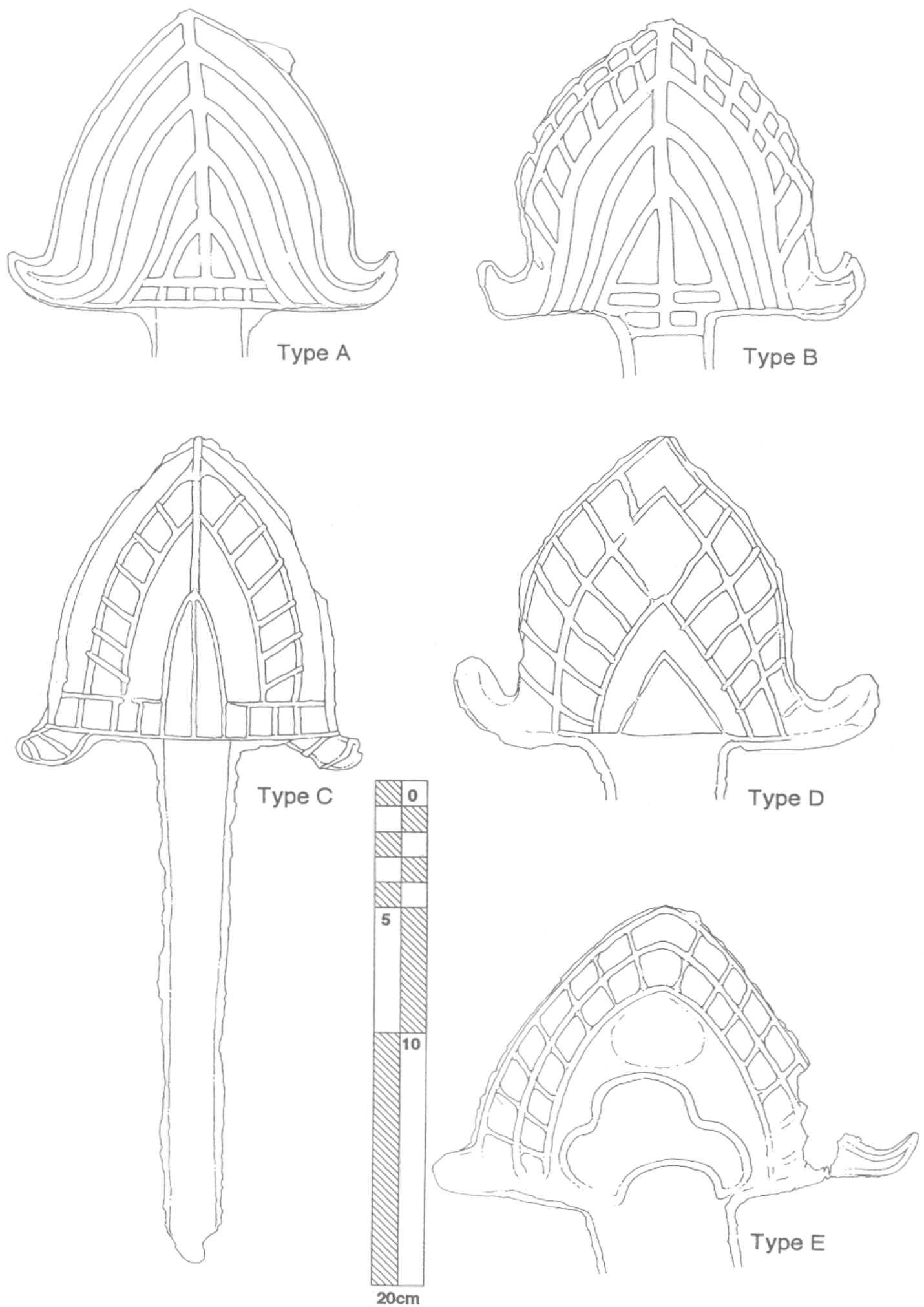

Planche 4: Antéfixes séries $\mathrm{A}$ à $\mathrm{E}$ 

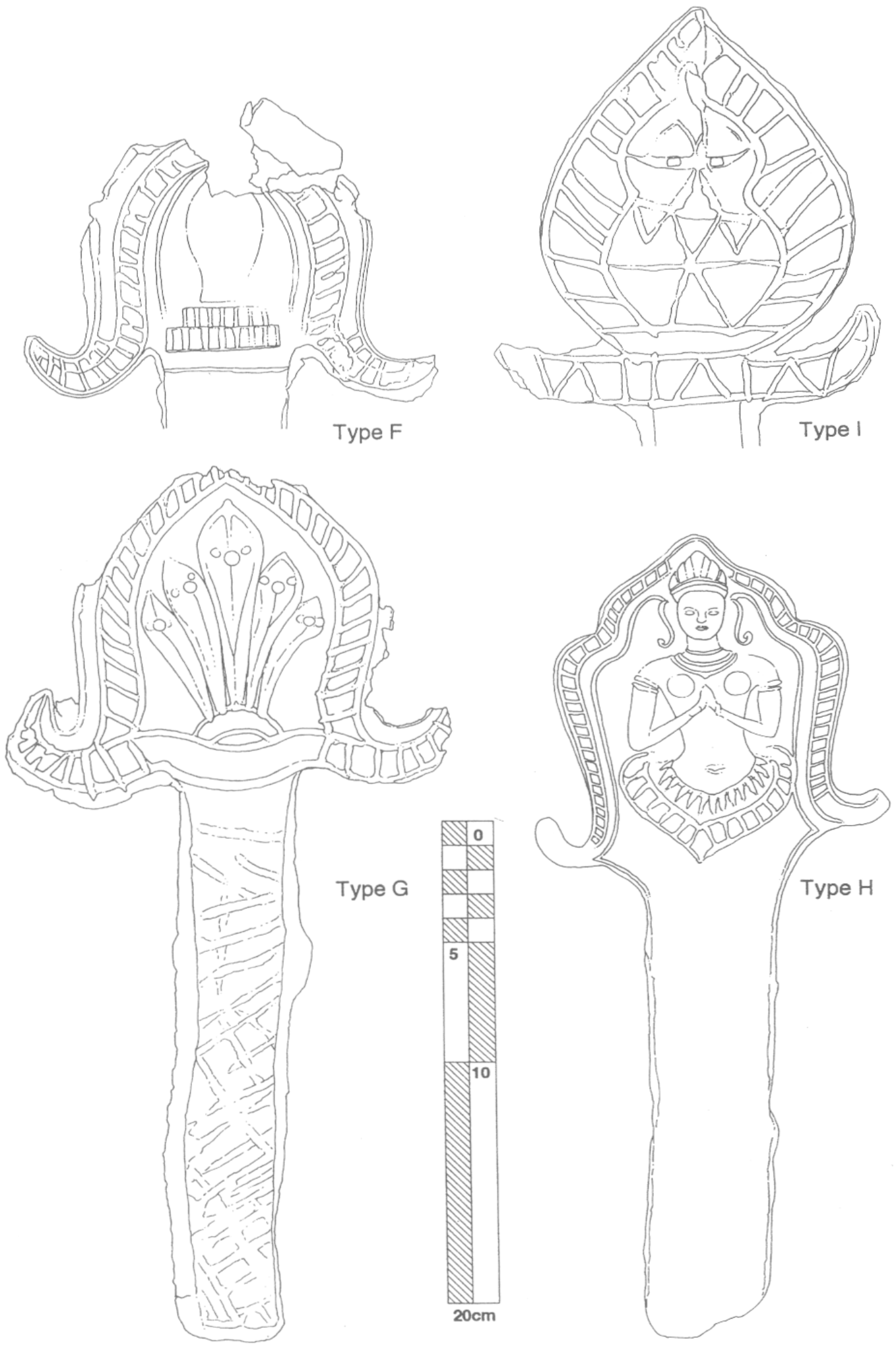

Planche 5: Antéfixes séries $\mathrm{F}$ à I 


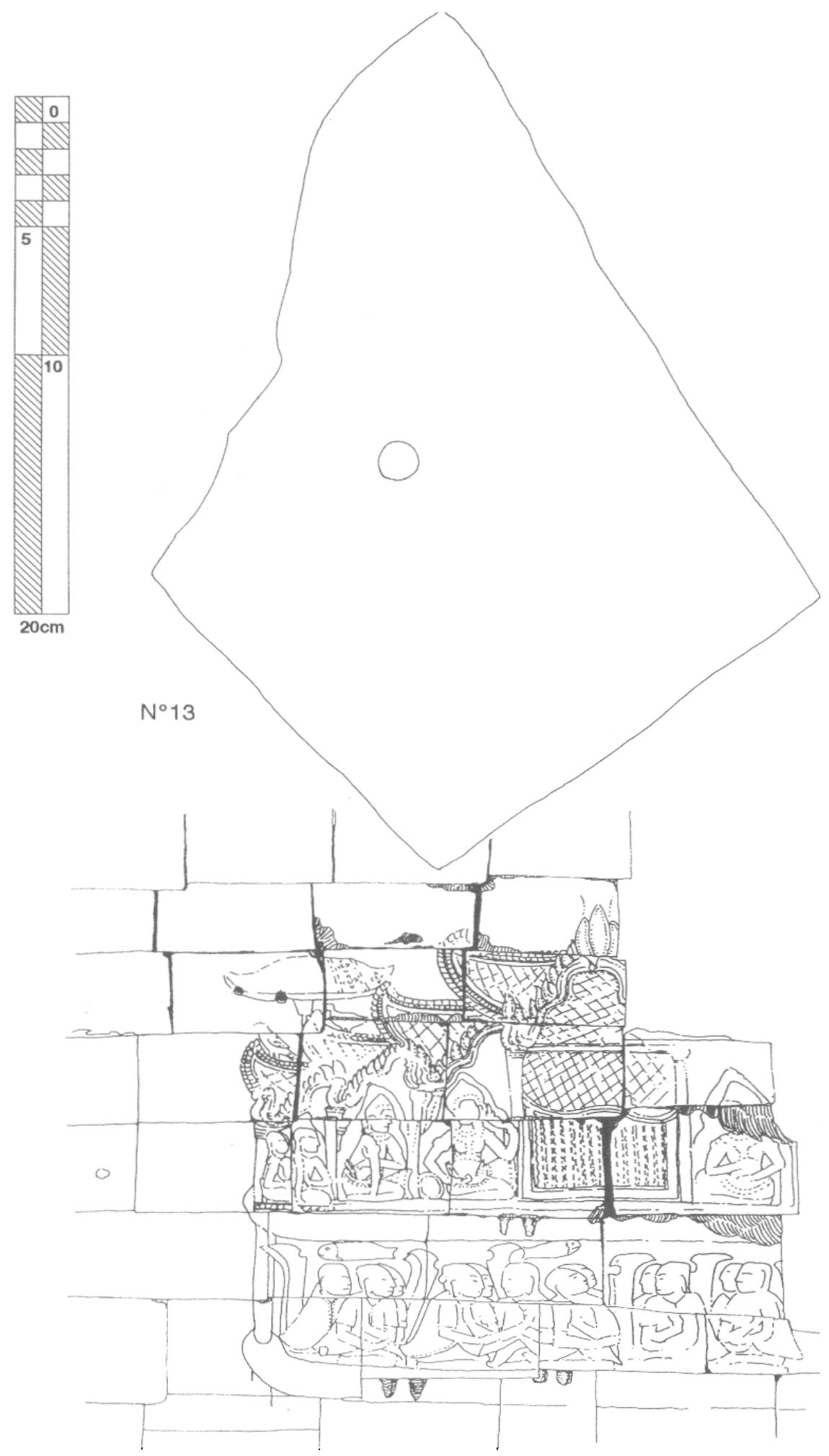

Planche 6. Tuile plate $n^{\circ} 13$ et détail d'un bas-relief du Bayon (galerie extérieure, face Sud, moitié Est, registre supérieur). 